\title{
REVIEW
}

\section{Colitis and Crohn's Foundation (India) consensus statements on use of 5 -aminosalicylic acid in inflammatory bowel disease}

\begin{abstract}
Ajit Sood ${ }^{1}$, Vineet Ahuja ${ }^{2}$, Vandana Midha ${ }^{3}$, Saroj Kant Sinha ${ }^{4}$, C. Ganesh Pai ${ }^{5}$, Saurabh Kedia ${ }^{2}$, Varun Mehta ${ }^{1}$, Sawan Bopanna ${ }^{6}$, Philip Abraham ${ }^{7}$, Rupa Banerjee ${ }^{8}$, Shobna Bhatia ${ }^{9}$, Karmabir Chakravartty $^{10}$, Sunil Dadhich ${ }^{11}$, Devendra Desai ${ }^{7}$, Manisha Dwivedi ${ }^{12}$, Bhabhadev Goswami ${ }^{13}$, Kirandeep Kaur ${ }^{14}$, Rajeev Khosla ${ }^{15}$, Ajay Kumar ${ }^{16}$, Ramit Mahajan ${ }^{1}$, S. P. Misra ${ }^{12}$, Kiran Peddi ${ }^{17}$, Shivaram Prasad Singh ${ }^{18}$, Arshdeep Singh ${ }^{1}$

${ }^{1}$ Department of Gastroenterology, Dayanand Medical College and Hospital, Ludhiana; ${ }^{2}$ Department of Gastroenterology, All India Institute of Medical Sciences, New Delhi, ${ }^{3}$ Department of Internal Medicine, Dayanand Medical College and Hospital, Ludhiana; ${ }^{4}$ Department of Gastroenterology, Postgraduate Institute of Medical Education and Research, Chandigarh; ${ }^{5}$ Department of Gastroenterology, Kasturba Medical College, Manipal; ${ }^{6}$ Fortis Hospital, New Delhi; ${ }^{7}$ P. D. Hinduja Hospital and Medical Research Centre, Mumbai; ${ }^{8}$ Asian Institute of Gastroenterology, Hyderabad; ${ }^{9}$ Department of Gastroenterology, King Edward Memorial Hospital, Mumbai; ${ }^{10}$ Department of Gastroenterology, AMRI Hospital, Kolkata; ${ }^{11}$ Department of Gastroenterology, Dr. Sampurnanand Medical College, Jodhpur; ${ }^{12}$ Department of Gastroenterology, Moti Lal Nehru Medical College, Allahabad: ${ }^{13}$ Department of Gastroenterology, Gauhati Medical College, Guwahati; ${ }^{14}$ Department of Pharmacology, Dayanand Medical College and Hospital, Ludhiana; ${ }^{15}$ Max Super Speciality Hospital, Saket, New Delhi; ${ }^{16}$ BLK Super Speciality Hospital, New Delhi; ${ }^{17}$ Citizens Centre for Digestive Disorders, Hyderabad; ${ }^{18}$ Department of Gastroenterology, Sriram Chandra Bhanj Medical College and Hospital, Cuttack, India
\end{abstract}

Despite several recent advances in therapy in inflammatory bowel disease (IBD), 5-aminosalicylic acid (5-ASA) therapy has retained its place especially in ulcerative colitis. This consensus on 5-ASA is obtained through a modified Delphi process, and includes guiding statements and recommendations based on literature evidence (randomized trials, and observational studies), clinical practice, and expert opinion on use of 5-ASA in IBD by Indian gastroenterologists. The aim is to aid practitioners in selecting appropriate treatment strategies and facilitate optimal use of 5-ASA in patients with IBD. (Intest Res 2020;18:355378)

Key Words: Inflammatory bowel disease; 5-Aminosalicylic acid; Crohn disease; Colitis, ulcerative; Mesalamine

\section{INTRODUCTION}

Since the beginning of 21st century, incidence of inflammatory bowel disease (IBD) has seen a steady rise in the emerging economies of Asia, Middle East, and South America. ${ }^{1}$ Amongst the Southeast Asian countries, disease burden seems to be

Received December 27, 2019. Revised March 18, 2020.

Accepted April 4, 2020

Correspondence to Ajit Sood, Department of Gastroenterology, Dayanand Medical College and Hospital, Ludhiana 141001, Punjab, India. Tel: +91-

9815400718, Fax:+91-161-2302620,E-mail: ajitsood10@gmail.com highest in India, with 2010 estimates pointing to an estimated IBD population of around 1.4 million. $^{2}$ There has been a progressively higher proportion of younger individuals being newly afflicted with the disease, along with ongoing aging of prevalent cases. Optimization of treatment modalities is critical as suboptimal disease management can lead to considerable morbidity and impairment of patients' functional capacity. ${ }^{3}$

5-Aminosalicylic acid (5-ASA; mesalamine/mesalazine) remains the drug of choice for management of a majority of patients with IBD. The anti-inflammatory effect of 5-ASA is through inhibition of lipoxygenase and cyclooxygenase en- 


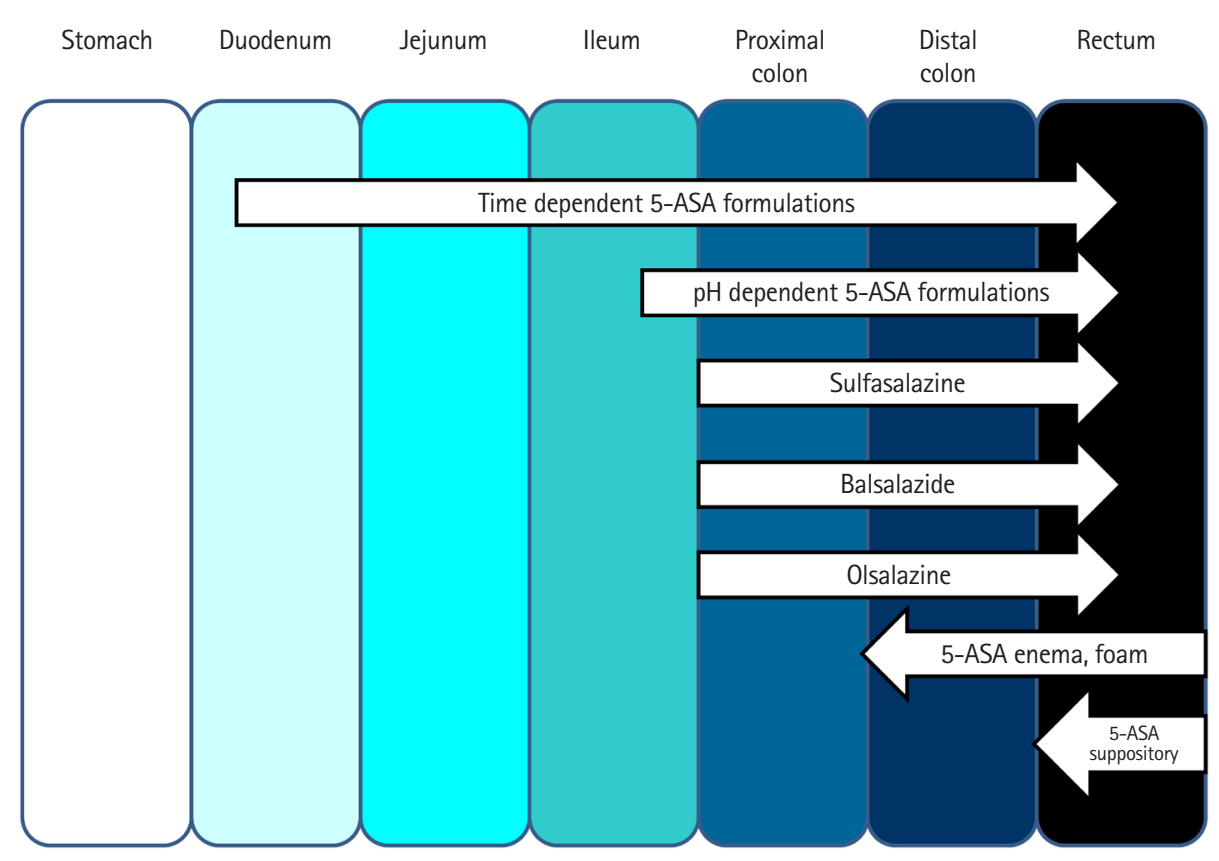

Fig. 1. Sites of 5-aminosalicylic acid (5-ASA) release from different formulations in the small and large intestine.

zymes, which in turn inhibit leucocyte chemotaxis to inflamed sites. 5-ASA can also activate peroxisome proliferator-activated receptor- $\gamma$, and has antioxidant and free-radical scavenging properties. $^{4-6}$

As the disease prevalence is on a steady rise, IBD management has come under the spotlight. Persistent efforts into research and development in IBD therapy have yielded several newer therapeutic options in recent years. However, 5-ASA has remained the drug of choice to date for management of a vast majority of patients with IBD. The journey of this seminal molecule in IBD started with the discovery of sulfasalazine. Over time it emerged that 5-ASA is the active therapeutic moiety. ${ }^{4,7}$ The efficacy of 5-ASA formulation depends on its topical effect rather than on systemic absorption and redistribution to target sites (Fig. 1). ${ }^{9-11}$ 5-ASA blood concentration is not related to the dose taken. ${ }^{12}$ This led to the development of newer 5-ASA drug delivery methods, aimed at minimizing systemic absorption and making maximum drug available at the inflamed epitheli-

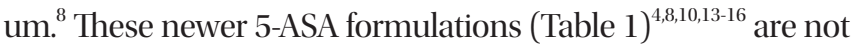
only efficacious but are also safe in the induction and maintenance of remission in IBD. They do not have the adverse effects of sulfasalazine, work locally at inflamed mucosa, and allow more proximal and pH-guided release (Fig. 1). ${ }^{4,8}$

Despite their benefits in ulcerative colitis (UC), the new 5-ASA formulations exhibit limited utility in Crohn's disease (CD). ${ }^{4,-9}$ The more recent formulations, such as microsphere encapsulated formulations, show a pH-independent delivery, with their site of release beginning at the duodenum and continuing throughout the intestinal tract, ${ }^{10}$ allowing their use in both UC and small-bowel CD. ${ }^{8}$ Further improvements, like granular drug formulations, have resulted in better outcomes than tablet forms. Rectal formulations such as suppositories and enemas have allowed better access to distal disease, thereby improving outcome.

With 5-ASA being the most commonly used drug in IBD, a need was felt to develop guidelines that would help optimize 5-ASA usage.

\section{METHODOLOGY}

\section{Sources and Search}

A comprehensive literature search was carried out on MEDLINE, MedIndia, EMBASE, and Cochrane Central Register of Controlled Trials for relevant literature published on use of 5-ASA in IBD. All the guidelines, original articles, systematic reviews, meta-analyses and review articles were included. Medical Subject Headings (MeSH) terms used to coin search strategies were "5-ASA," "5 aminosalicylic acid," "ulcerative colitis," "Crohn's colitis," “colitis gravis," “inflammatory bowel disease," "IBD," "bowel diseases, inflammatory," "idiopathic proctocolitis," "mesalamine," "sulfasalazine," "olsalazine," "balsalazide," “mesalazine," “Crohn disease," “Crohn's disease," and 
Table 1. 5-ASA Formulations and Site of Action

\begin{tabular}{|c|c|c|c|c|c|c|}
\hline Formulation & Dispensed as & Name & $\begin{array}{c}\text { Standard oral } \\
\text { dose (g/day) }\end{array}$ & Technology & Drug release & $\begin{array}{l}\text { Site of drug } \\
\text { release }\end{array}$ \\
\hline \multirow[t]{2}{*}{ pH dependent } & Tablets & Mesalamine & $\begin{array}{l}\text { 2.4-4.8 (multiple } \\
\text { daily doses) }\end{array}$ & Mesalamine coated with Eudragit $S$ resin ${ }^{a}$ & Delayed; $\mathrm{pH}>7$ & $\begin{array}{l}\text { Terminal ileum, } \\
\text { colon }\end{array}$ \\
\hline & Tablets & Mesalamine & $2.4-4.8$ (OD dosing) & $\begin{array}{l}\text { Mesalamine coated with Eudragit L\&S } \\
\text { resin }^{a} \text { or } \\
\text { Dual acting hydrophilic matrix technology }\end{array}$ & $\begin{array}{l}\text { Delayed; } \mathrm{pH} \\
\quad>6-7\end{array}$ & $\begin{array}{l}\text { Terminal ileum, } \\
\text { colon }\end{array}$ \\
\hline Time dependent & $\begin{array}{l}\text { Tablets, granule } \\
\text { sachets }\end{array}$ & Mesalamine & $\begin{array}{l}\text { 2-4 Can be given } \\
\text { in OD dosing }\end{array}$ & Ethylcellulose coated micro granules & Controlled & $\begin{array}{l}\text { Duodenum to } \\
\text { colon }\end{array}$ \\
\hline Topical & $\begin{array}{r}\text { Enema, foam, } \\
\text { suppository }\end{array}$ & Mesalamine & 1 & $\begin{array}{l}\text { Enema } \\
\text { Foam } \\
\text { Suppository }\end{array}$ & Topical & $\begin{array}{l}\text { Distal colon and } \\
\text { rectum }\end{array}$ \\
\hline \multirow[t]{3}{*}{$\begin{array}{l}\text { Azo-bonded } \\
\text { prodrugs }\end{array}$} & Tablets & Sulfasalazine & $2-4$ & 5-ASA linked to sulfapyridine by azo bond & $\begin{array}{l}\text { Cleavage by } \\
\text { intestinal flora }\end{array}$ & Colon \\
\hline & Capsules & Olsalazine & $2-3$ & 5-ASA dimer linked by azo bond & $\begin{array}{l}\text { Cleavage by } \\
\text { intestinal flora }\end{array}$ & Colon \\
\hline & Tablets & Balsalazide & $2-6.75$ & $\begin{array}{l}\text { 5-ASA linked to 4-aminobenzoyl-b- } \\
\text { alanine by azo bond }\end{array}$ & $\begin{array}{l}\text { Cleavage by } \\
\text { intestinal flora }\end{array}$ & Colon \\
\hline
\end{tabular}

${ }^{a}$ Eudragit $\mathrm{S}$ coating: dissolves at $\mathrm{pH} \geq 7$; Eudragit $\mathrm{L}$ coating: dissolves at $\mathrm{pH} \geq 6 .{ }^{8}$ To the best of our knowledge, no formulation is based on multi-matrix system technology in India. ${ }^{4,8,10,13-16}$

5-ASA, 5-aminosalicylic acid; OD, once daily.

Table 2. Grade of Recommendation and Level of Evidence

\begin{tabular}{|c|c|c|c|}
\hline \multicolumn{2}{|r|}{ Quality of evidence } & \multicolumn{2}{|r|}{ Strength of recommendation } \\
\hline Grade & Description & Grade & Description \\
\hline I & $\begin{array}{l}\text { Evidence obtained from at least one meta analysis/systematic review/randomized } \\
\text { controlled trial }\end{array}$ & A & There is good evidence to support the statement \\
\hline$\|-1$ & Evidence from well controlled trials without randomization & B & There is fair evidence to support the statement \\
\hline$\|-2$ & Evidence from well designed cohort or case control study & C & There is poor evidence to support the statement \\
\hline III & Opinion of experienced authorities and expert committees & $\mathrm{E}$ & There is good evidence to refute the statement \\
\hline
\end{tabular}

Indian Society of Gastroenterology guideline methodology ${ }^{20}$ which was a modified version of the scheme suggested by the Canadian Task Force on the Periodic Health Examination. ${ }^{19}$

“Crohn's Enteritis."

\section{Review and Grading of Evidence}

The Grading of Recommendation Assessment, Development and Evaluation (GRADE) approach was used to assess the quality of evidence in systematic reviews, randomized controlled trials (RCTs), observational studies and practice guidelines. ${ }^{17,18}$ GRADE process helps in rating the quality of collected and summarized evidences based on explicit criteria that consider study design, risk of bias, and magnitude of effect. It also helps in considering whether the evidence is imprecise, inconsistent, or indirect. Recommendations were then classified as strong or weak based on the quality of the supporting evidence and after balancing the desirable and undesirable consequences of other management options. ${ }^{18}$ The methodology used was a modified version of the scheme suggested by the Canadian Task Force on Periodic Health Examination. ${ }^{19}$ The level of evidence was divided into I, II-1, II-2, II-3 and III; and grade of recommendations classified as A, B, C, D, and E (Table 2). ${ }^{19,20}$

\section{Consensus Process}

A modified Delphi process was used for arriving at the consensus. ${ }^{21}$ Based on literature search results, statements were proposed and were circulated amongst eminent gastroenter- 
ologists who are key opinion leaders (KOLs) in their field and region. Prior to sharing the proposed statements for voting, consent was sought from each prospective participant. Nine areas pertaining to the use of 5-ASAs in IBD were identified viz induction of remission, maintenance of remission, role of rectal 5-ASAs in UC, duration of use, role in CD, use in mother and child, side effects and monitoring, chemoprevention, and adherence. The questionnaire had one section for each of the areas. Each statement had 4 voting options: strongly agree, agree, disagree, and strongly disagree.

First round of voting was held through an anonymous online survey. After the first round of voting, the available evidence for the proposed statement in questionnaire was shared with the KOLs. A face-to-face meeting was held, where literature evidence was presented by 6 KOLs for each proposed statement. Based on discussion amongst the KOLs, a final round of voting (live anonymous vote using voting pads) was carried out during the meeting and consensus was achieved for each statement. When there was no consensus on a particular statement, it was modified. A second vote was sought for this modified statement and it was retained as a recommendation if voting was in favor and deleted if voting was against or inconclusive. The formal method that was used for development of consensus, based on the modified Delphi process is shown in Fig. $2 .^{21}$

\section{RECOMMENDATION STATEMENTS REGARDING 5-AMINOSALICYLATES}

The recommended statements include the level of supporting evidence, grade of recommendation, and voting results. This is followed by a discussion of the supporting evidence. A summary of the recommended statements is provided in Table 3.

\section{Role of 5-ASA in Induction of Remission in UC}

\section{Statement 1}

5-ASA containing formulations are effective for induction of remission in patients with mild to moderate UC of any extent and are the first line of treatment for this indication.

- Grade of recommendation: A, Level of evidence: I, Voting: $87.5 \%$ strongly agree, $12.5 \%$ agree

Two RCTs conducted in 1960s have shown that sulfasalazine (2-4 g/day) was more effective than placebo in induction of remission. However, it was not well tolerated due to adverse events and high rates of discontinuation were observed. ${ }^{22,23}$

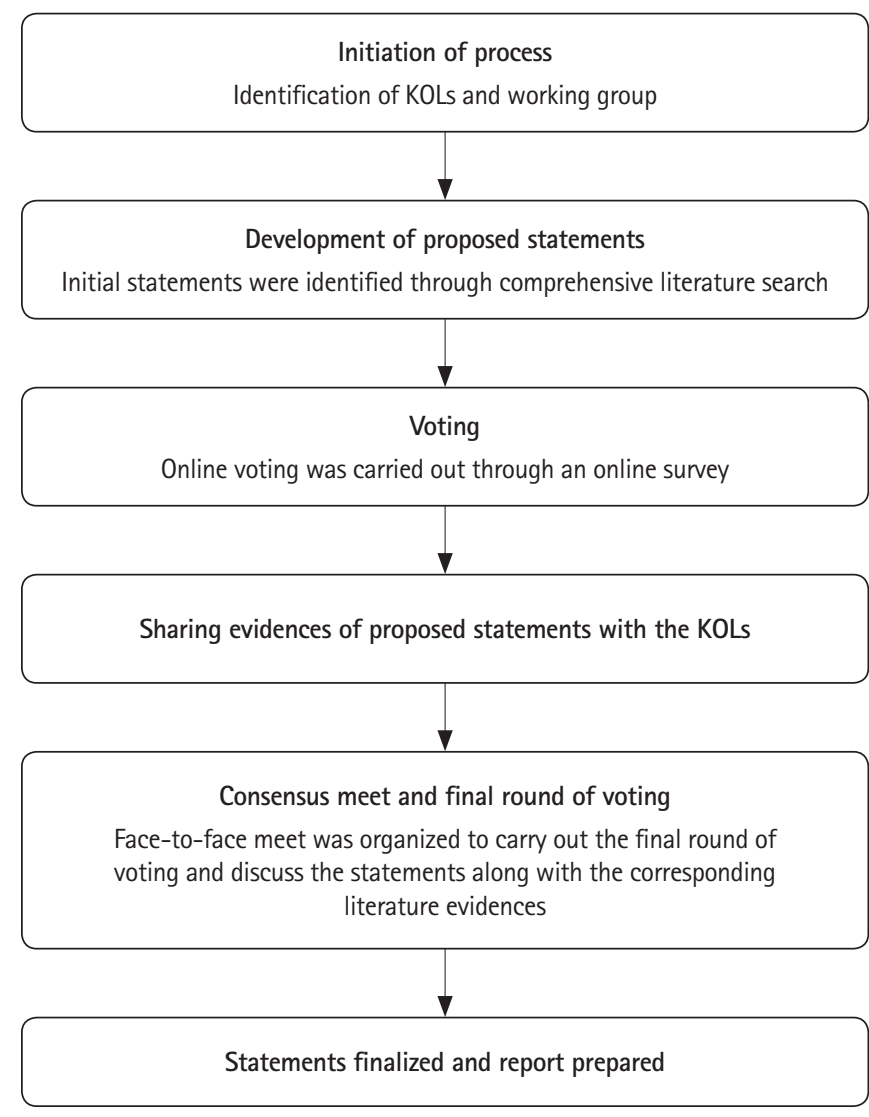

Fig. 2. A modified Delphi process. The Delphi method: techniques and application. ${ }^{21} \mathrm{KOLs}$, key opinion leaders.

Subsequently, all other 5-ASA formulations (low, standard, and high-dose mesalamine and diazo-bonded 5-ASAs) have been shown to be superior to placebo in inducing remission in adults with left-sided or extensive mild-to-moderate UC in a systematic review and network meta-analysis including 48 induction RCTs $(\mathrm{n}=8,020){ }^{24}$

A Cochrane review conducted by Feagan and MacDonald (48 studies including RCTs; 7,776 patients) was further updated by Wang et al. (53 studies including RCTs, $\mathrm{n}=8,548$ ) to assess the efficacy of 5-ASA. ${ }^{25,26}$ Wang et al. ${ }^{26}$ found 5-ASA to be significantly superior to placebo for all outcome variables (failure to enter clinical remission $71 \%$ in 5-ASA vs. $83 \%$ in placebo group: relative risk [RR], 0.86; 95\% confidence interval [CI], 0.82-0.89) in active mild-to-moderate UC. The different formulations of 5-ASA (tablets, granules, pellets, delayed release preparations of mesalamine, balsalazide and olsalazine) did not differ in efficacy (failure to enter remission in patients on 5-ASA vs. patients on comparator 5-ASA 50\% vs. 52\%: RR, $0.94 ; 95 \%$ CI, $0.86-1.02)^{25,26}$

For patients with mild to moderately severe UC, 5-ASA is 
Table 3. Summary of Consensus Recommendations for the Medical Management of IBD

\begin{tabular}{|c|c|}
\hline Statement No. & Statements \\
\hline \multicolumn{2}{|c|}{ Induction of remission in UC } \\
\hline 1 & $\begin{array}{l}\text { 5-ASA containing formulations are effective for induction of remission in patients with mild to moderate UC of any extent and are the } \\
\text { first line of treatment for this indication. Grade of recommendation: A, Level of evidence: I }\end{array}$ \\
\hline 2 & $\begin{array}{l}\text { In mild to moderate UC, 5-ASA (2-4.8 g/day) or sulfasalazine (3 g/day) should be given for induction of remission. Grade of } \\
\text { recommendation: A, Level of evidence: I }\end{array}$ \\
\hline 3 & $\begin{array}{l}\text { In distal/extensive UC, the combination of topical and oral 5-ASA formulations is preferred over oral 5-ASA agent alone. Grade of } \\
\text { recommendation: A, Level of evidence: I }\end{array}$ \\
\hline 4 & $\begin{array}{l}\text { Once daily dose of oral sustained released preparation should be considered as it is equally effective as divided doses. Grade of } \\
\text { recommendation: A, Level of evidence: I }\end{array}$ \\
\hline 5 & $\begin{array}{l}\text { A period of } 2 \text { weeks of 5-ASA therapy should be given before considering a patient as a nonresponder (patients failing to show } \\
\text { improvement post 5-ASA therapy). Grade of recommendation: B, Level of evidence: I }\end{array}$ \\
\hline 6 & $\begin{array}{l}\text { Dose escalation to a maximum dose of 4-4.8 g may be done for patients who do not respond to lower initiating doses of 5-ASA } \\
\text { compounds. Grade of recommendation: B, Level of evidence: I }\end{array}$ \\
\hline 7 & Sulfasalazine may be preferred in patients with concomitant arthralgia/arthritis. Grade of recommendation: C, Level of evidence: III \\
\hline 8 & $\begin{array}{l}\text { In acute severe colitis, 5-ASA has no proven role as an adjunct therapy. 5-ASA should be introduced after clinical improvement. Grade } \\
\text { of recommendation: C, Level of evidence: III }\end{array}$ \\
\hline \multicolumn{2}{|c|}{ Maintenance of remission in UC } \\
\hline 9 & Long-term 5-ASA is indicated for maintenance of remission in patients with UC. Grade of recommendation: A, Level of evidence: I \\
\hline 10 & $\begin{array}{l}\text { In patients with mild to moderate UC, the dose that was used for induction of remission should be continued for initial maintenance of } \\
\text { remission. Grade of recommendation: } B_{1} \text { Level of evidence: I }\end{array}$ \\
\hline 11 & $\begin{array}{l}\text { 5-ASA maintenance dose reduction can be considered in patients with UC having mild clinical course with complete mucosal healing. } \\
\text { Grade of recommendation: B, Level of evidence: II-1 }\end{array}$ \\
\hline 12 & $\begin{array}{l}\text { For patients with moderate to severe UC, who required corticosteroids for induction of remission, 5-ASA should be continued for } \\
\text { maintenance. Grade of recommendation: B, Level of evidence: II-2 }\end{array}$ \\
\hline 13 & $\begin{array}{l}\text { Patients with proctitis can be maintained with } 3 \mathrm{~g} \text { weekly divided dose of topical 5-ASA or low dose of oral 5-ASA (2-2.4 g daily). Grade } \\
\text { of recommendation: A, Level of evidence: I }\end{array}$ \\
\hline
\end{tabular}

\section{Role of rectal formulations in UC}

14 In patients with proctitis, suppository should be preferred over enema or foam. Grade of recommendation: A, Level of evidence: I

15 Recommended dosage of topical therapy with 5-ASA suppository for induction of remission is $1 \mathrm{~g}$ once daily. Grade of recommendation: A, Level of evidence: I

In ulcerative proctitis, topical 5-ASA formulations in the form of suppository/enema are the first line of therapy. Patients not responding to topical treatment can be given a combination of oral and topical 5-ASA. Grade of recommendation: A, Level of evidence: I

In patients with proctitis not responding to oral and rectal 5-ASA, topical corticosteroids can be added for inducing remission. Grade of recommendation: A, Level of evidence: I

\section{How long to use 5-ASA?}

18 The decision to continue or withdraw 5-ASA should depend on several factors including mucosal healing, the duration of remission, extent of disease, and frequency of side effects experienced by the patients. Grade of recommendation: B, Level of evidence: I

19 In patients with proctitis with mucosal healing, oral 5-ASA may be discontinued with continuation of rectal suppositories. Grade of

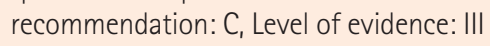

\section{Role in CD}

20 Sulfasalazine may be considered for induction of remission in mild to moderate colonic CD. Grade of recommendation: B, Level of evidence: I

21 5-ASA formulations are not indicated for induction of remission in ileal/ileocolonic/proximal small intestinal CD. Grade of recommendation: $A$, Level of evidence: I

22 There is no role of 5-ASA or sulfasalazine in maintenance of remission in a majority of patients with CD. Grade of recommendation: A, Level of evidence: I

23 5-ASA has a role for postoperative prophylaxis following ileal resection in CD. Grade of recommendation: A, Level of evidence: I 
Table 3. Continued

\begin{tabular}{|c|c|}
\hline Statement No. & Statements \\
\hline \multicolumn{2}{|c|}{ Use of 5-ASA in pregnant/lactating women and children with IBD } \\
\hline 24 & $\begin{array}{l}\text { 5-ASA agents are the first-line therapy for induction and maintenance of remission in children with UC. Grade of recommendation: } \mathrm{A} \text {, } \\
\text { Level of evidence: I }\end{array}$ \\
\hline 25 & $\begin{array}{l}\text { Suggested dosing is oral mesalamine } 60-80 \mathrm{mg} / \mathrm{kg} / \text { day to } 4.8 \mathrm{~g} \text { daily; rectal mesalamine } 25 \mathrm{mg} / \mathrm{kg} \text { check up to } 1 \mathrm{~g} \text { daily; sulfasalazine } \\
40-70 \mathrm{mg} / \mathrm{kg} / \text { day up to } 4 \mathrm{~g} \text { daily. Grade of recommendation: B, Level of evidence: I }\end{array}$ \\
\hline 27 & 5-ASA is safe in lactating mothers. Grade of recommendation: $C_{1}$ Level of evidence: II-3 \\
\hline
\end{tabular}

\section{Side effects and monitoring}

28 5-ASA is well tolerated by most patients. Grade of recommendation: A, Level of evidence: I

29 Paradoxical worsening of colitis may occur on initiation of 5-ASA due to drug hypersensitivity and requires discontinuation of the drug. Grade of recommendation: A, Level of evidence: I

30 5-ASA may cause renal toxicity and therefore monitoring of renal function should be carried out at least once in a year. Grade of recommendation: $A$, Level of evidence: I

31 Dose modification is not required in chronic renal failure except that renal function should be monitored more closely. Grade of

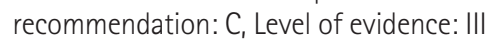

32 Although, sulfasalazine has the potential to cause decreased fertility in men, 5-ASA formulations do not affect fertility in men or women. Grade of recommendation: B, Level of evidence: II-1

33 Folate supplementation is required with use of sulfasalazine, other 5-ASA formulations do not require it. Grade of recommendation: B, Level of evidence: II-3

\section{Chemoprevention}

34 Long-term 5-ASA therapy in extensive/distal colitis is possibly associated with reduced risk of colon cancer in UC. Grade of recommendation: $\mathrm{B}$, Level of evidence: II-1

\section{Adherence}

35 Adherence to 5-ASA therapy improves outcome in patients with IBD. Hence, patient education is important. Grade of recommendation: B, Level of evidence: II-2

5-ASA, 5-aminosalicylic acid; IBD, inflammatory bowel disease; UC, ulcerative colitis; CD, Crohn's disease.

widely accepted for use as first line therapy in induction of remission. ${ }^{10}$ Head to head comparisons between 5-ASA and corticosteroids are very few. ${ }^{27}$ A multicenter, randomized, single blind, parallel group study comparing beclomethasone and 5-ASA found similar efficacy in both treatment arms at 4 weeks (remission achieved in $63.0 \%$ vs. $62.5 \%$ of patients, respectively). ${ }^{28}$

\section{Statement 2}

In mild to moderate UC, 5-ASA (2-4.8 g/day) or sulfasalazine ( $3 \mathrm{~g} /$ day) should be given for induction of remission.

- Grade of recommendation: A, Level of evidence: I, Voting: $78.3 \%$ strongly agree, $21.7 \%$ agree

The Assessing the Safety and Clinical Efficacy of a New Dose of 5-ASA (ASCEND) trials were a series of dose-finding trials for 5-ASA in UC. A pooled analysis of 3 ASCEND trials showed no significant difference between $4.8 \mathrm{~g} /$ day and $2.4 \mathrm{~g} /$ day in mild to moderately active UC (RR, 0.89; 95\% CI, 0.78-1.01). ${ }^{25,26}$ Subgroup analysis however, showed that the patients with moderate UC benefited from a higher dose viz. $4.8 \mathrm{~g} / \mathrm{day}^{29}$

In another systematic review and network meta-analysis by Nguyen et al. ${ }^{24}$ when UC was stratified by disease severity ( 6 RCTs, $\mathrm{n}=1,589$ patients with extensive or left-sided mild to moderate UC), high-dose 5-ASA ( $>3$ g/day) was shown to be superior to standard-dose (2-3 g/day) for inducing clinical remission (RR, 0.92; 95\% CI, 0.86-0.99). Therefore, 5-ASA can be used in low dose ( $2.4 \mathrm{~g} /$ day) in mild UC and higher doses (4.8 $\mathrm{g} /$ day) can be used in moderately severe disease.

Sulfasalazine at a dose of $3 \mathrm{~g} /$ day has been used for inducing remission in patients with mild to moderate UC., ${ }^{4,630}$ Two Cochrane systematic reviews showed that efficacy of different 5-ASA formulations and sulfasalazine was not significantly different (RR, 0.90; 95\% CI, 0.77-1.04). ${ }^{25,26}$ On the contrary, compared to diazo-bonded 5-ASAs, sulfasalazine was inferior in 
inducing clinical remission. ${ }^{24}$ Furthermore, 5-ASA is better tolerated than sulfasalazine with $29 \%$ and $15 \%$ of patients experiencing adverse events on sulfasalazine and 5-ASA, respectively (RR, 0.48; 95\% CI, 0.37-0.63). ${ }^{25}$

\section{Statement 3}

In distal or extensive mild to moderate UC, combination of topical and oral 5-ASA formulations is preferred over oral 5-ASA alone.

- Grade of recommendation: A, Level of evidence: I, Voting: $91.7 \%$ strongly agree, $4.2 \%$ agree, $4.2 \%$ disagree

A systematic review and meta-analysis of 4 RCTs found combined topical and oral 5-ASAs to be superior to oral 5-ASA alone in inducing remission in mild to moderate active leftsided UC, proctosigmoiditis, and proctitis (RR of no remission, 0.65; 95\% CI, 0.47-0.91). ${ }^{31}$ Another systematic review and network meta-analysis $(\mathrm{n}=8,020$ patients with extensive or leftsided mild to moderate UC) reported that combined oral and rectal 5-ASA agents were superior to standard dose oral 5-ASA (2-3 g/day) for induction of remission (failure to induce remission with combined oral and rectal 5-ASAs; odds ratio [OR], 0.41; 95\% CI, 0.22-0.77). ${ }^{24}$ Active comparisons of efficacy and tolerability showed that combined oral and rectal 5-ASAs were significantly superior to all other interventions for inducing remission in mild to moderate UC, except budesonide multi-matrix. ${ }^{24}$ In the surface under the cumulative ranking curve analysis (SUCRA), combined oral and rectal 5-ASAs ranked highest in inducing remission (SUCRA, 0.99) followed by high-dose 5-ASA (SUCRA, 0.82). ${ }^{24}$ Considering $13 \%$ median remission rate for placebo across trials, approximately $63 \%$, $33 \%$, and $26 \%$ of patients treated with combined oral and rectal 5-ASA, high-dose and standard-dose 5-ASA, respectively, are expected to achieve clinical remission. ${ }^{24}$

\section{Statement 4}

Once daily dose of oral sustained release preparation should be considered as it is equally effective as divided doses.

- Grade of recommendation: A, Level of evidence: I, Voting: $72.0 \%$ strongly agree, $28.0 \%$ agree

New, once daily (OD) formulations of 5-ASA use multi-matrix technology which involves incorporating 5-ASA into a lipophilic matrix, which itself is dispersed within a hydrophilic matrix, to delay and prolong the dissolution. ${ }^{32}$ Two Cochrane systematic reviews have demonstrated no significant difference between OD versus conventional dosing for induction of remission $(P=0.49$ and $P=0.34$ respectively $){ }^{25,26}$ In a metaanalysis (7 RCTs, $\mathrm{n}=1,469$ ), no significant differences were observed between OD and multiple dosing groups for induction of remission in mild to moderate UC (RR, 1.03; 95\% CI, 0.97-1.10; $P=0.26) .{ }^{33}$ A single daily dose of 5-ASA should therefore be preferred as in addition to being equally efficacious, it improves patient compliance. ${ }^{34,35}$ It should be taken into consideration that 5-ASA formulations available in India do not use multi-matrix technology. They use a dual matrix technology with L and S Eudragit coating.

\section{Statement 5}

A period of 2 weeks of 5-ASA therapy should be given before considering a patient as a nonresponder.

- Grade of recommendation: B, Level of evidence: I, Voting: $80.0 \%$ strongly agree, $20.0 \%$ agree

While selecting 5-ASA for induction of remission in patients with UC, the timing at which clinical response is evident also needs to be considered. Nonresponders to the recommended 5-ASA induction doses should be identified early, and therapy escalation should be considered in such cases.

Based on ASCEND ( $4.8 \mathrm{~g} /$ day, $800 \mathrm{mg}$ tablet) I and II trials, symptoms of rectal bleeding and stool frequency either improved or resolved by day 14 in the majority of patients on both $4.8 \mathrm{~g}$ /day and $2.4 \mathrm{~g} /$ day of 5-ASA (73\% vs. $61 \%$, respectively). By day 14 , symptom resolution was seen in $43 \%$ versus $30 \%$ of patients on $4.8 \mathrm{~g} /$ day versus $2.4 \mathrm{~g} /$ day dose $(P=0.035)$ Moreover, relief in symptoms after 2 weeks correlated with high rate of relief in symptoms after 6 weeks. ${ }^{36}$ Hence, patients should be assessed at day 14 for therapeutic decision making.

\footnotetext{
Statement 6

Dose escalation to a maximum dose of 4-4.8 $\mathrm{g}$ may be done for patients who do not respond to lower initiating doses of 5-ASA compounds.

- Grade of recommendation: B, Level of evidence: I, Voting: $76.0 \%$ strongly agree, $24.0 \%$ agree
}

In the ASCEND I trial, subgroup analysis of patients with moderately active disease revealed that higher dose of 5-ASA was better by an absolute difference of $15 \%$ in achieving therapeutic success ( $72 \%$ vs. $57 \%, P=0.038) .{ }^{37}$ ASCEND II confirmed a statistically superior effect of the $4.8 \mathrm{~g} /$ day over the $2.4 \mathrm{~g} /$ day dose in moderately active disease $(72 \%$ overall response vs. 59\%, respectively) ${ }^{38}$ and ASCEND III showed a significant benefit of $4.8 \mathrm{~g} /$ day versus $2.4 \mathrm{~g} /$ day in patients with difficult to treat UC, specifically those who required cortico- 
steroids or more than 2 medications (corticosteroids, oral 5-ASA, rectal 5-ASA, or immunomodulators) for disease control in the past. ${ }^{39}$

A systematic review and network meta-analysis $(n=8,020)$ has also ranked high-dose 5-ASA ( $>3 \mathrm{~g} /$ day) superior to standard-dose 5-ASA (2-3 g/day) for induction of remission (failure to induce remission with high-dose 5-ASA; OR, 0.78; 95\% CI, 0.66-0.93). ${ }^{25}$ These trials suggest that in patients not responding to lower initiating doses of 5-ASA, dose escalation to $4.8 \mathrm{~g} /$ day should be tried by week 3 before considering addition of corticosteroids, immunosuppressants/immunomodulators or biologics for such cases.

\section{Statement 7}

Sulfasalazine may be preferred in patients with concomitant arthralgia/arthritis.

- Grade of recommendation: C, Level of evidence: III, Voting: $100.0 \%$ strongly agree

Articular involvement is the most common extraintestinal manifestation in IBD, with a prevalence ranging between $17 \%$ and $39 \%{ }^{40}$ It frequently involves the axial joints but can also be associated with peripheral arthritis. Peripheral arthritis has 3 subtypes: type 1, pauciarticular, joint activity parallels intestinal disease activity, type 2, polyarticular form, affecting small joints with symptoms running independent from IBD course, and type 3, which includes both axial and peripheral forms. ${ }^{41-43}$

The approach to management of arthritis in patients with IBD is similar to that in treatment of spondyloarthritis. While the treatment of axial arthritis focuses on combination of exercise and nonsteroidal anti-inflammatory drugs (NASIDs), selective conventional non-biologic disease-modifying antirheumatic drugs (DMARDs) are used for peripheral arthritis resistant to initial NSAID therapy, if biologics are not already required for axial or gastrointestinal disease manifestations. ${ }^{44}$

Sulfasalazine is one such DMARD, which is an azo-bonded combination of 5-ASA and sulfapyridine. It is often poorly tolerated due to adverse effects (due to the sulfapyridine moiety) such as headache, nausea, vomiting, drug rash, hepatitis, and hematologic toxicity. This limits its use in IBD, for which safer 5-ASA compounds have been developed. However, an Italian Expert panel has recommended 2-3 g/day of sulfasalazine in mild to moderate IBD with peripheral arthritis and early disease that failed on intra-articular corticosteroids. ${ }^{45}$ On the other hand, the Assessment in SpondyloArthritis international Society and European League Against Rheumatism do not recommend sulfasalazine for management of ankylosing spondylitis (and thus axial arthritis). ${ }^{46}$ Thus, sulfasalazine can be used in patients with IBD who have concomitant peripheral arthritis but may not be beneficial for those with axial arthritis.

\section{Statement 8}

In acute severe colitis, 5-ASA has no proven role as an adjunct therapy. 5-ASA should be introduced after clinical improvement.

- Grade of recommendation: C, Level of evidence: III, Voting: $59.3 \%$ strongly agree, $33.3 \%$ agree, $7.4 \%$ disagree

Acute severe UC is a medical emergency with high mortality. Intravenous corticosteroids remain the cornerstone of treatment, as they act rapidly and are effective in up to $70 \%$ of the patients. ${ }^{47,48} 5$-ASAs can be temporarily withdrawn while the patients are being treated with intravenous corticosteroids, as there is no evidence supporting benefit of these drugs in acute severe UC. Conversely, a paradoxical increase in diarrhea has been reported in 3\% patients on 5-ASAs. ${ }^{48,49}$ However, topical 5-ASA or corticosteroids may be added in patients who have high stool frequency. ${ }^{20}$ After an initial response to the intravenous corticosteroids, patients can be switched to oral corticosteroids, and 5-ASA, azathioprine, or 6-mercaptopurine can be added $^{50}$

\section{Role of 5-ASA in Maintenance of Remission in UC}

\section{Statement 9}

Long-term 5-ASA is indicated for maintenance of remission in patients with UC.

- Grade of recommendation: A, Level of evidence: I, Voting: $100.0 \%$ strongly agree

\section{Statement 10}

In patients with mild to moderate UC, the dose that was used for induction of remission should be continued for initial maintenance of remission.

- Grade of recommendation: B, Level of evidence: I, Voting: $53.8 \%$ strongly agree, $23.1 \%$ agree, $23.1 \%$ disagree

The safety and efficacy of long-term use of 5-ASA as a maintenance therapy has been studied in several studies and its continued use is known to prevent disease relapse in patients with UC., ${ }^{910}$

A Cochrane review of 38 studies $(n=8,127)$ assessed efficacy, dose-responsiveness, and safety of oral 5-ASA for maintenance of clinical or endoscopic remission in UC. Forty-one 
per cent of 5-ASA patients relapsed compared to $58 \%$ of placebo patients ( 7 studies, 1,298 patients; RR, 0.69; 95\% CI, 0.62$0.77){ }^{25,51}$ Another network meta-analysis (28 RCTs; $\mathrm{n}=4,218$ ) also showed that all of the following were effective at remission maintenance; low dose 5-ASA ( $<2 \mathrm{~g}$ /day), standard dose 5-ASA ( $<2-3$ g/day), high-dose 5-ASA ( $>3$ g/day). Diazo bonded 5-ASAs and combined oral and rectal 5-ASAs were significantly superior to placebo in maintaining clinical remission in UC (diazo-bonded 5-ASAs: RR, 0.47; 95\% CI, 0.35-0.62; oral and rectal 5-ASAs: RR, 0.21; 95\% CI, 0.11-0.40). Sulfasalazine tended to be superior to placebo in maintaining clinical remission in UC (RR, $0.81 ; 95 \% \mathrm{CI}, 0.57-1.17){ }^{24}$

A randomized open-label study including 156 UC patients in remission, who had experienced a disease relapse within previous 3 months, were randomized to receive either $2.4 \mathrm{~g} /$ day or $1.2 \mathrm{~g} /$ day 5-ASA dose for 12 months. The patients on 2.4 $\mathrm{g}$ /day dose had significantly higher mean number of days to relapse than those prescribed $1.2 \mathrm{~g} /$ day dose (mean \pm standard deviation: $175 \pm 126$ vs. $129 \pm 95.3, P<0.001$, respectively). ${ }^{52}$ In patients who experienced $\leq 3$ relapses/year in the 3 years prior to enrollment, more number of the patients in the $2.4 \mathrm{~g} /$ day group were maintained in remission than in the $1.2 \mathrm{~g} /$ day group. ${ }^{52}$

\section{Statement 11}

5-ASA maintenance dose reduction can be considered in patients with UC having mild clinical course with complete mucosal healing.

- Grade of recommendation: B, Level of evidence: II-1, Voting: $73.1 \%$ strongly agree, $19.2 \%$ agree, $7.7 \%$ disagree

Mucosal healing in UC is associated with improved clinical outcomes in terms of lower relapse rates, ${ }^{53-55}$ lesser requirement for immunosuppressive agents, ${ }^{56}$ fewer hospitalizations and colectomies, ${ }^{56,57}$ lower risk of colorectal cancer $^{58-60}$ and improved quality of life. ${ }^{61,62}$ Achieving complete mucosal healing should, therefore, be the primary endpoint of treatment.

Besides mucosal healing, various factors including adherence to treatment, duration of disease in remission, degree of mucosal healing (complete/partial), and clinical course should be considered before reducing the maintenance dose of 5-ASA.

No difference in the long-term risk of flare was noted between low (2.4-2.8 g/day) versus high (4.4-4.8 g/day) dose 5-ASA in patients who adhere to treatment. ${ }^{63}$ Data from an IBD registry showed that a longer duration ( $>2$ years) of disease remission correlated with a lower risk of relapse $(P<0.001) .{ }^{64}$
In another randomized, double-blind withdrawal study using 5-ASA $1.2 \mathrm{~g} /$ day, patients were allocated to 2 groups according to length of previous remission. In the group in remission for over 24 months, withdrawal of 5-ASA did not influence the relapse rates. ${ }^{65}$

No difference was found in another study in relapse rates at 1 year on 5-ASA $1.2 \mathrm{~g}$ compared with $2.4 \mathrm{~g} /$ day. However, for patients with extensive UC, 5-ASA agents in a dose of $1.2 \mathrm{~g} /$ day were inferior to $2.4 \mathrm{~g} /$ day for long-term maintenance of remission $(P<0.005)$. The $1.2 \mathrm{~g} /$ day dose was also significantly $(P=$ 0.01 ) inferior to $2.4 \mathrm{~g} /$ day for patients with frequently relapsing disease. $^{52}$

A recent study, including UC patients in remission, showed that 5-ASA dose reduction is more successful in sustaining remission if Mayo endoscopic sub-score of 0 is achieved ${ }^{66}$ In the MOMENTUM trial, of patients who achieved remission during induction with high-dose multi-matrix 5-ASA, $47.8 \%$ of patients in complete remission and $26 \%$ of patients in partial remission could achieve/maintain remission after 12 months at a reduced dose of $2.4 \mathrm{~g} /$ day $(\mathrm{OR}, 2.61 ; 95 \% \mathrm{CI}, 1.76-3.87 ; P<0.001)$ emphasizing that patients achieving complete remission before dose reduction were more likely to sustain remission. ${ }^{67}$

Complete withdrawal of 5-ASA agents is currently not recommended unless the patient is intolerant as there is some evidence that regular 5-ASA reduces the risk of colorectal cancer. ${ }^{68}$ Hence, the decision of dose reduction should be undertaken with caution and may be considered in patients with mild disease course and where mucosal healing has been observed for at least 2 years.

\section{Statement 12}

For patients with moderate to severe UC who required corticosteroids for induction of remission, 5-ASAs can be used for maintenance.

- Grade of recommendation: B, Level of evidence: II-2, Voting: $96.4 \%$ strongly agree, $3.6 \%$ agree

Use of corticosteroids for inducing remission is associated with an increased risk of subsequent clinical relapses. ${ }^{69}$ Studies evaluating outcomes after systemic corticosteroid use have shown that up to $30 \%-40 \%$ patients subsequently require medical rescue therapies or colectomy. ${ }^{70-72}$

In a cohort of UC patients treated with 5-ASA after a course of oral systemic corticosteroids, $75 \%$ patients relapsed (median, 29 months; range, 1-156 months), and 14\% required colectomy (median, 11 months; range, 1-24 months). Kaplan Meier curve showed relapse and colectomy rates over 1 year 
of $26 \%$ and $11 \%$, respectively. ${ }^{73}$ Khan et al. ${ }^{74}$ also reported that $65 \%$ of patients who achieved clinical remission with corticosteroids required retreatment with steroids within 2 years. Seventy-two percent relapse rate at 83 months follow-up in patients with steroid induced remission was reported in another study. ${ }^{75}$

The use of corticosteroids as maintenance therapy is restricted by lack of long-term efficacy, and associated side-effects. ${ }^{76,77}$ In a report from an IBD registry on patients receiving 5-ASA as maintenance therapy for UC, Fukuda et al. ${ }^{64}$ concluded that patients with history of steroid use have a tendency to relapse. These patients can be maintained on 5-ASA therapies or on thiopurines. For those not willing for thiopurines, 5-ASA therapy is a suitable option. However, the dose of 5-ASA should not be reduced, especially in patients with previous corticosteroid use, as these patients are at risk for clinical relapse.

\section{Statement 13}

Patients with proctitis can be maintained with $3 \mathrm{~g}$ weekly divided dose of topical 5-ASA or low dose of oral 5-ASA (22.4 g daily).

- Grade of recommendation: A, Level of evidence: I, Voting: $55.6 \%$ strongly agree, $40.7 \%$ agree, $3.0 \%$ strongly disagree

Rectal 5-ASA is first-line maintenance therapy in ulcerative proctitis. An RCT with 95 ulcerative proctitis patients found 5-ASA suppositories at a dose of $1 \mathrm{~g}$ thrice a week to be more effective than placebo in maintaining remission. ${ }^{78}$ Another RCT reported a significantly higher relapse rate at 12 and 24 months with placebo as compared to OD 500-mg 5-ASA suppository $(P<0.001) .{ }^{79}$ A systematic review and meta-analysis evaluating topical 5-ASA therapies for maintenance of remission in ulcerative proctitis also reported the benefit of rectal 5-ASA (pooled RR, 2.80; 95\% CI, 1.21-6.45; degree of heterogeneity $\left.\left[\mathrm{I}^{2}\right], 66 \% ; P=0.02\right){ }^{80}$ Another recent meta-analysis including 7 RCTs ( $\mathrm{n}=555$ ), showed that topical 5-ASA was effective in preventing relapse of distal UC. ${ }^{81}$ The superiority of rectal 5-ASA over placebo for maintenance of remission at 1 year was also demonstrated in a recent Cochrane review (RR, 2.22; $95 \%$ CI, $1.26-3.90){ }^{82}$

Two RCTs have compared combination treatment with oral 5-ASA plus intermittent 5-ASA enema and oral 5-ASA alone, for maintenance of remission. One compared patients who received $1 \mathrm{~g}$ 5-ASA enemas twice a week plus oral 5-ASA $3 \mathrm{~g} /$ day for 7 days with daily oral 5-ASA only and the other compared combined therapy with 5-ASA tablets $1.6 \mathrm{~g}$ /day and
5-ASA enemas $4 \mathrm{~g} / 100 \mathrm{~mL}$ twice weekly with oral 5-ASA tablets $1.6 \mathrm{~g}$ /day and placebo enemas/twice weekly. ${ }^{83,84}$ Higher remission rates were reported in patients receiving combination therapy.

Long-term tolerance and adherence to rectal therapy is variable. ${ }^{85,86}$ Oral 5-ASAs associated with better patient compliance could be an alternative if rectal therapies are not tolerated. The newer oral 5-ASA formulations including the ethylcellulose coated as well as multi-matrix 5-ASA have been shown to achieve therapeutic levels in the distal colon. ${ }^{87,88}$

\section{Role of Rectal 5-ASA Formulations in UC}

\section{Statement 14}

In patients with proctitis, suppositories should be preferred over enemas or foams.

- Grade of recommendation: A, Level of evidence: I, Voting: $88.9 \%$ strongly agree, $11.1 \%$ agree

\section{Statement 15}

Recommended dosage of topical therapy with 5-ASA suppository for induction of remission is $1 \mathrm{~g} \mathrm{OD}$.

- Grade of recommendation: A, Level of evidence: I, Voting: 92.3\% strongly agree, $7.7 \%$ agree

\section{Statement 16}

In ulcerative proctitis, topical 5-ASA formulations in the form of suppository/enema, is the first line of therapy. Patients not responding to topical treatment can be given a combination of oral and topical 5-ASA.

- Grade of recommendation: A, Level of evidence: I, Voting: $87.0 \%$ strongly agree, $13.0 \%$ agree

Various 5-ASA rectal formulations (enemas, foams, and suppositories) are available for treatment of ulcerative proctitis. Suppositories target the site of the inflammation in the rectum and the distribution mirrors the extent of disease. Foams and enemas can act topically in the sigmoid and descending colon respectively and therefore are preferred treatment in left-sided colitis. $^{89,90}$

Römkens et al. ${ }^{91}$ in their meta-analysis (2,513 patients using rectal 5-ASA) reported mucosal healing rates of $62 \%, 51 \%$, and $46 \%$ for suppositories (8 study arms), foams (9 study arms), and enema (23 study arms), respectively. On subgroup analysis, head to head comparison between 5-ASA foam and enema did not reveal significant difference between the preparations. Because suppositories are used in patients with proctitis and represent a different group of patients, direct comparison with other preparations were not done. 
Additionally, during acute flares, enemas are generally less well tolerated as a larger volume of enema is difficult to retain because of active rectal inflammation. ${ }^{92-94}$ OD topical therapy is as effective as divided doses. In a randomized clinical trial, 5-ASA $1 \mathrm{~g}$ OD suppository was compared with conventional $500 \mathrm{mg}$ twice a day 5-ASA suppository in patients with active distal UC. The OD treatment resulted in quicker induction of clinical and endoscopic remission and was better tolerated than twice daily group $(P<0.01){ }^{95}$ Another randomized multicenter trial demonstrated non-inferiority of $1 \mathrm{~g}$ OD 5-ASA suppository versus $500 \mathrm{mg}$ 5-ASA suppository thrice-daily, with patients preferring the OD regime. ${ }^{96}$ There is no dose response for topical therapy above a dose of $1 \mathrm{~g}$ 5-ASA daily. ${ }^{97}$

Although 5-ASA suppositories produce earlier and significantly better results than oral 5-ASA in the treatment of active ulcerative proctitis, patients intolerant/nonresponsive to rectal 5-ASA alone can be treated with oral 5-ASA in combination with rectal 5-ASA therapies. ${ }^{98,99}$

A double-blind comparison of oral versus rectal 5-ASA versus combination therapy in the treatment of distal UC concluded that combination of oral and rectal 5-ASA was more effective than either alone. ${ }^{100}$ Another randomized multicenter study demonstrated a significantly higher rate of improvement in UC-Disease Activity Index (UC-DAI) within 2 weeks with the combined oral 5-ASA/enema therapy $(P=0.032)$ in extensive colitis. ${ }^{101}$ There are no trials of combination therapy for proctitis alone.

\section{Statement 17}

In patients with proctitis not responding to oral and rectal 5-ASA, topical corticosteroids can be added for inducing remission.

- Grade of recommendation: A, Level of evidence: I, Voting: $76.0 \%$ strongly agree, $24.0 \%$ agree

Two meta-analyses have shown that topical 5-ASA is more effective than topical corticosteroids, in inducing symptomatic, endoscopic, or histological remission. ${ }^{97,102}$ However, in patients not responding/intolerant to 5-ASA (topical, oral or a combination of both) within 2-3 weeks of initiating therapy, combination therapy of topical 5-ASA and topical corticosteroids can be considered. ${ }^{94} \mathrm{~A}$ randomized, double-blind trial demonstrated higher efficacy of beclomethasone dipropionate (BDP) and 5-ASA enema combination therapy (BDP/5-ASA) versus BDP or 5-ASA alone. The combination was significantly superior to single-agent therapy in terms of improved endoscopic and histological scores. ${ }^{103}$

\section{How Long to Use 5-ASAs?}

\section{Statement 18}

Withdrawal of 5-ASAs is associated with a significant risk of relapse. Decision to withdraw should only be made after several factors are taken into consideration such as duration of remission and mucosal healing.

- Grade of recommendation: B, Level of evidence: I, Voting:

$42.9 \%$ strongly agree, $46.4 \%$ agree, $10.7 \%$ disagree

Multiple factors determine the duration of treatment with 5-ASA. A recent Cochrane review suggested that 5-ASA was superior to placebo as a maintenance therapy in UC. ${ }^{82}$ These findings endorse a lifelong approach to therapy with 5-ASA in UC. However, dose reduction after induction of remission has been evaluated in various studies.

In a real-world OPTIMUM study, no difference was found between reduced dose and maintained dose for maintenance of remission after induction. Also, maintenance of remission was noted to be significantly better than placebo in patients in whom duration of remission was $>12$ months (hazard ratio [HR] for relapse, $0.600 ; 95 \% \mathrm{CI}, 0.486-0.740 ; P<0.0001$ for $>12$ months and HR, 0.352; 95\% CI, 0.289-0.431; $P<0.0001$ for $>24$ months). 5-ASA therapy was not withdrawn in any of the patient. ${ }^{104}$ In a retrospective Korean study, left-sided or extensive colitis at time of diagnosis (HR, 1.46; 95\% CI, 1.01-2.10; $P=0.04$ ) was observed to be independent predictor for clinical relapse on 5-ASA therapy. ${ }^{105}$

Although 5-ASA preparations are generally well tolerated, adverse reactions including worsening colitis; nephrotoxicity, interstitial lung disease, bronchiolitis obliterans, pancreatitis, hair loss, and Stevens-Johnson syndrome have been described. ${ }^{106}$ These can also be major determinants in deciding continuation or withdrawal of the therapy.

Mucosal healing (endoscopic/histological) also predicts the subsequent clinical course. Narang et al. ${ }^{107}$ showed that histological remission predicts a sustained clinical remission (87.1\% patients in histological remission remained asymptomatic at 1 year). Another RCT showed that 5-ASA dose reduction is more successful in sustaining remission if a Mayo endoscopic sub-score of 0 is achieved. ${ }^{66}$ Attainment of mucosal healing might help decide upon the withdrawal or discontinuation of the drug.

Complete withdrawal of 5-ASA agents is currently not recommended unless the patient is intolerant as there is some evidence that regular 5-ASA reduces the risk of colorectal cancer. ${ }^{68}$ 


\section{Statement 19}

In patients with proctitis with mucosal healing, oral 5-ASA may be discontinued with continuation of rectal suppositories.

- Grade of recommendation: C, Level of evidence: III, Voting: $92.6 \%$ strongly agree, $7.4 \%$ agree

A meta-analysis involving 3,977 patients on oral 5-ASA (granules and tablets) and 2,513 patients on rectal 5-ASA (suppositories, enema, and foam) demonstrated that mucosal healing rates are superior with rectal formulations (36.9\% and $50.3 \%$ for patients treated with oral and topical mesalamine, respectively). ${ }^{91}$ Another systematic review by Ford et al. ${ }^{81}$ that studied the relative efficacies of different routes of administration of 5-ASA agents also concluded that intermittent topical 5-ASAs are superior to oral 5-ASA in maintaining remission in quiescent UC.

Though there is no direct evidence showing the benefit of discontinuing oral 5-ASA and continuing suppositories in patients with proctitis who have achieved mucosal healing, the expert panel recommends that oral 5-ASA may be discontinued with continuation of rectal suppositories in such patients.

\section{Role of 5-ASA in CD}

\section{Statement 20}

Sulfasalazine may be considered for induction of remission in mild to moderate colonic CD.

- Grade of recommendation: B, Level of evidence: I, Voting: $37.5 \%$ strongly agree, $54.2 \%$ agree, $8.3 \%$ disagree

A Cochrane meta-analysis has evaluated the role of aminosalicylates in induction of remission or response in CD. A pooled analysis of 3 studies $^{108-110}$ showed that sulfasalazine was not superior to placebo for induction of remission or response at 17 to 26 weeks of follow-up (RR, 1.52; 95\% CI, 0.95$2.43 ; P=0.08)$; however, because of sparse data and heterogeneity the results had low quality of GRADE evidence. ${ }^{108}$ A subsequent comparison of 2 RCTs. ${ }^{109,110}$ after removing the source of heterogeneity revealed a favorable response with sulfasalazine over placebo after 17-18 weeks of follow-up (RR, 1.38; 95\% CI, 1.00-1.89; $P=0.05$; zero heterogeneity; and moderate quality of evidence). There was no difference in adverse events between sulfasalazine and placebo arms. ${ }^{108}$ The benefit however was limited to patients with Crohn's colitis. Those patients with small bowel disease or those who continued to have active disease even after previous corticosteroid and sulfasala- zine exposures were not likely to benefit. ${ }^{108,109}$ The 5-ASA formulations do not have efficacy in isolated colonic CD.

\section{Statement 21}

5-ASA formulations are not indicated for induction of remission in ileal/ileocolonic/proximal small intestinal CD. - Grade of recommendation: A, Level of evidence: I, Voting: $63.0 \%$ strongly agree, $22.2 \%$ agree, $11.1 \%$ disagree, $3.7 \%$ strongly disagree

Comparison between sulfasalazine and corticosteroids showed that sulfasalazine monotherapy was inferior to corticosteroids at 17-18 weeks of follow-up (RR, 0.68; 95\% CI, 0.51-0.91; $P=0.009$; moderate quality of evidence due to sparse data). ${ }^{108}$ Another pooled analysis showed that controlled release 5-ASA (1-2 g/day) was not superior to placebo at 16 weeks of followup (RR, 1.46; 95\% CI, 0.89-2.40; $P=0.14$ ). There was no difference in proportion of patients having adverse effects. ${ }^{108}$

A pooled analysis of 3 studies comparing 5-ASA ( $4 \mathrm{~g} /$ day) with placebo showed a nonsignificant mean difference in Crohn's Disease Activity Index (CDAI) reduction (-19.8 points; $95 \% \mathrm{CI},-46.2$ to $6.7 ; P=0.14)$; another comparison of delayed release 5-ASA (3-4.5 g/day) with tapering dose conventional corticosteroids showed no significant difference in efficacy after 8-12 weeks of follow-up (RR, 1.04; 95\% CI, 0.79-1.36). ${ }^{108}$

Comparison of 5-ASA $4 \mathrm{~g}$ /day with budesonide $9 \mathrm{mg}$ /day showed that 5-ASA was significantly less effective than budesonide at 16 weeks (RR, 0.56; 95\% CI, 0.40-0.78; $P<$ $0.001) .{ }^{108}$ There was significant difference in proportion of patients experiencing adverse effects, however, more patients withdrew from 5-ASA arm due to adverse effects. Another trial corroborated these findings when olsalazine $2 \mathrm{~g} /$ day led to a higher withdrawal rate, mainly due to diarrhea, as compared with placebo $(P=0.015) .{ }^{108}$

Although the Cochrane analysis has limitations of sparse data, trial heterogeneity and high risk of bias, yet, it has been sufficiently demonstrated that sulfasalazine was modestly effective, with benefit confined to Crohn's colitis; and there is no proven role of 5-ASA in induction of remission in ileal/ileocolonic/proximal small intestinal CD.

\section{Statement 22}

There is no role of 5-ASA or sulfasalazine in maintenance of remission in a majority of patients with $\mathrm{CD}$.

- Grade of recommendation: A, Level of evidence: I, Voting: $50.0 \%$ strongly agree, $37.5 \%$ agree, $12.5 \%$ disagree

The efficacy of sulfasalazine or 5-ASA in maintaining remis- 
sion in CD is not documented. ${ }^{110,111} \mathrm{~A}$ systematic review of 12 RCTs found no significant difference in relapse at 12 and 24 months between the 5-ASA and placebo arms. The relapse at 12 months was 53\% in 5-ASA patients (dose 1.6-4 g/day) versus $54 \%$ placebo patients (RR, 0.98 ; $95 \%$ CI, $0.91-1.07$; 11 studies, 2,014 patients). ${ }^{112}$ Likewise, $54 \%$ (31/57) of 5-ASA patients (dose $2 \mathrm{~g}$ /day) relapsed at 24 months compared to 58\% (36/62) of placebo patients (RR, 0.94; 95\% CI, 0.68-1.29; 119 patients). ${ }^{112}$

However, 5-ASA may prove to be of utility in certain patients with CD as reported by a retrospective analysis by Danish Crohn Colitis Database Study among 165 CD patients. A long term benefit was observed with 5-ASA in $36 \%$ of the patients. ${ }^{113}$ Twenty-three percent of patients became 5-ASA dependent (responding to re-introduction of 5-ASA on relapsing within a year of 5-ASA cessation or to dose escalation on relapsing on stable/reduced 5-ASA dose). Women were more likely than men to develop response to 5-ASA (OR, 2.89; 95\% CI, $1.08-7.75 ; P=0.04)$. Patients with longer disease duration were more likely to show 5-ASA dependency (38\% vs. 18\%: OR, 4.06; 95\% CI, 1.09-15.1; $P=0.04) .{ }^{113}$

Outcome on 5-ASA in CD is not associated with localization or behavior of disease, age, or history of surgery. ${ }^{113}$

\section{Statement 23}

5-ASA has a role in postoperative prophylaxis following ileal resection in CD.

- Grade of recommendation: A, Level of evidence: I, Voting: $56.5 \%$ strongly agree, $39.1 \%$ agree, $4.3 \%$ disagree

A Cochrane systematic review of 23 RCTs that investigated medical therapies for postoperative $\mathrm{CD}$ recurrence reported that clinical recurrence and severe endoscopic recurrence reduced significantly with 5-ASA as compared with placebo (RR for clinical recurrence, 0.76 ; 95\% CI, 0.62-0.94; number needed to treat $[\mathrm{NNT}]=12$; RR for severe endoscopic recurrence, 0.50 ; $95 \%$ CI, 0.29-0.84; NNT = 8). Risk of serious adverse events was lower with 5-ASA versus azathioprine/6-mercaptopurine (RR, $0.51 ; 95 \%$ CI, 0.30-0.89) but risk of any endoscopic recurrence was higher (RR, 1.45; 95\% CI, 1.03-2.06). 5-ASA therapy did not differ significantly from azathioprine/6-mercaptopurine for any other outcome. ${ }^{49}$

Another Cochrane systematic review of 9 RCTs found that 5-ASA was significantly more effective than placebo in postoperative prophylaxis of $\mathrm{CD}(\mathrm{OR}, 0.68$; 95\% CI, $0.52-0.90)$, but there was no difference in efficacy between 5-ASA and thiopurines (OR, 1.08; 95\% CI, 0.63-1.85).$^{114}$

\section{Use of 5-ASA in Pregnant/Lactating Women and Children with IBD}

\section{Statement 24}

5-ASA agents are the first line therapy for induction and maintenance of remission in children with UC.

- Grade of recommendation: A, Level of evidence: I, Voting: $70.8 \%$ strongly agree, $29.2 \%$ agree, $4.2 \%$ disagree

5-ASAs are recommended as first-line therapy for induction and maintenance of remission of mild to moderate UC in children. ${ }^{15,116} 5$-ASA therapy should be used for maintenance indefinitely unless intolerant, as it is highly effective and has a good safety profile.

A prospective cohort study successfully reported clinical remission at week 3 in $42 \%$ pediatric patients treated with the combination of 5-ASA oral and enema $(1 \mathrm{~g} /$ day $) .{ }^{117}$ In a randomized, double-blind, active control study, pediatric UC patients treated with high and low-dose 5-ASA for a period of 6 weeks demonstrated similar efficacy in improving Pediatric UC Activity Index (55\% vs. 56\% of the patients in high- and low-dose of 5-ASA, respectively) $(P=0.924)$ as well as Truncated Mayo score (70\% vs. 73\%) ${ }^{118}$ An RCT comparing efficacy of once and twice daily dosing of 5-ASA in inducing remission in children with UC did not find any significant difference in the rates of induction of remission $(60 \%$ vs. $63 \%, P=0.78) .{ }^{119}$

A meta-analysis including 37 RCTs revealed that 5-ASA is highly effective for induction of remission (RR of no remission 0.79 with 5-ASAs; $95 \%$ CI, $0.73-0.85$; $\mathrm{NNT}=6$ ). Higher effect was observed at $\geq 2.0 \mathrm{~g} /$ day dose (RR, 0.91; 95\% CI, 0.85-0.98). ${ }^{120}$ However, there is no increase in remission rates at doses of $>2.5 \mathrm{~g} /$ day

5-ASA is also effective in preventing relapse of quiescent UC as compared to placebo (RR of relapse, 0.65 ; $95 \%$ CI, $0.55-$ 0.76 ; NNT $=4)$. Doses $\geq 2.0 \mathrm{~g} /$ day were more effective in preventing relapse as compared to $<2.0 \mathrm{~g} /$ day $(\mathrm{RR}, 0.79 ; 95 \% \mathrm{CI}$, 0.64-0.97). ${ }^{120}$ A multicenter, double-blind study on 68 patients with mild-to-moderate active UC in the age range 5 to 17 years, reported an achievement of clinical improvement in $45 \%$ and $37 \%$ of patients who received 5-ASA agent (oral balsalazide) 6.75 and $2.25 \mathrm{~g} /$ day, respectively while clinical remission was seen in $12 \%$ and $9 \%$ of patients respectively. The study supported the tolerability and safety profile of 5-ASA and its role in clinical remission in pediatric UC patients. ${ }^{121}$ In another multicenter, randomized, double-blind study, 39\% pediatric mild to moderate UC patients clinically improved with olsalazine and were asymptomatic after 3 months, com- 
pared to $79 \%$ on sulfasalazine ( $P=0.006)$; however, side effects were slightly less frequent with olsalazine. ${ }^{122}$ Heyman et al. ${ }^{123}$ suggested that a daily dose of $500 \mathrm{mg}$ 5-ASA suppository to be safe and effective in pediatric ulcerative proctitis patients. At weeks 3 and 6, the mean Disease Activity Index values, with daily bedtime $500 \mathrm{mg}$ 5-ASA suppository, decreased from 5.5 at baseline to 1.6 and 1.5 , respectively $(P<0.001)$.

A meta-analysis including 20 RCTs comparing 5-ASA and sulfasalazine however, yielded nonsignificant differences. The RR for overall improvement was 1.04 (95\% CI, 0.89-1.21; $P=0.63$ ), RR for relapse was 0.98 (95\% CI, 0.78-1.23; $P=0.85$ ), RR for any adverse events was 0.76 (95\% CI, $0.54-1.07 ; P=0.11$ ), and RR for withdrawals due to adverse events was 0.78 (95\% CI, 0.46- $1.3 ; P=0.33){ }^{124}$

\section{Statement 25}

Suggested dosing is oral 5-ASA 60 to $80 \mathrm{mg} / \mathrm{kg} /$ day to $4.8 \mathrm{~g}$ daily; rectal 5-ASA $25 \mathrm{mg} / \mathrm{kg}$ up to $1 \mathrm{~g}$ daily; sulfasalazine $40-70 \mathrm{mg} / \mathrm{kg} /$ day up to $4 \mathrm{~g}$ daily.

- Grade of recommendation: B, Level of evidence: I, Voting: $72.7 \%$ strongly agree, $27.3 \%$ agree

An RCT enrolled 83 pediatric patients (age group: $5-17$ years) who were treated with low dose delayed release 5-ASA viz. 27-71 mg/g/day and high dose delayed release 5-ASA viz. 53$118 \mathrm{mg} / \mathrm{g} /$ day. Both low- and high-dose arms demonstrated similar efficacy in 81 of 83 modified intent to treat population in short term treatment of mild to moderate active UC. ${ }^{118}$ In another Phase I RCT, 52 children with UC, aged 5 to 17 years, and stratified by weight (18-82 kg), received multi-matrix 5-ASA at doses of 30, 60, or $100 \mathrm{mg} / \mathrm{kg} /$ day OD (maximum $4,800 \mathrm{mg} /$ day) for 7 days. Children and adolescents with UC had pharmacokinetic profiles of 5-ASA and metabolite acetyl5-ASA similar to historical adult cohort. ${ }^{125}$ Children can therefore receive a dose that is similar to the adult dose.

In an open-label trial 5-ASA $500 \mathrm{mg}$ suppository daily at bedtime was found to be efficacious and safe in children with ulcerative proctitis. ${ }^{123} 5$-ASA enemas in the dose of $25 \mathrm{mg} / \mathrm{kg}$ (up to $1 \mathrm{~g}$ ) daily for 3 weeks along with oral dose, can induce clinical remission and response in $42 \%$ and $71 \%$ pediatric UC patients, respectively, after 3 weeks. ${ }^{117}$

\section{Statement 26}

Treatment with 5-ASA or sulfasalazine, if effective, should be continued during pregnancy as available evidence does not suggest adverse fetal outcomes.

- Grade of recommendation: A, Level of evidence: I, Voting: $77.3 \%$ strongly agree, $22.7 \%$ agree
Safety of 5-ASA therapy was established in a meta-analysis including 642 pregnant IBD patients treated with 5-ASA, sulfasalazine or olsalazine. There was no significant increase in the risks of stillbirth (OR, $2.38 ; P=0.32)$, spontaneous abortion (OR, 1.14; $P=0.74$ ), preterm delivery (OR, $1.35 ; P=0.26$ ) low birth weight (OR, $0.93 ; P=0.96)$ and congenital abnormalities (OR, 1.16; $P=0.57) .{ }^{126} 5$-ASA and sulfasalazine have been found to be safe in placebo-controlled studies in doses up to 3 g/day. ${ }^{127-129}$ Folate supplementation has been recommended along with sulfasalazine. However, doses higher than $3 \mathrm{~g} /$ day might increase the risk of congenital malformations, premature birth, miscarriage, and fetal nephrotoxicity. ${ }^{127-129}$

Presence of dibutylphthalate (DBP) in certain 5-ASA preparations, (using > 190 times the recommended human dose) is associated with an increased risk of development of skeletal malformations and reproductive adverse effects in animals. However, there are little data on effects of DBP among humans. ${ }^{130}$

\section{Statement 27}

5-ASA is safe in lactating mothers.

- Grade of recommendation: C, Level of evidence: II-3, Voting: $68.0 \%$ strongly agree, $32.0 \%$ agree

Breast feeding might be protective against early onset IBD. ${ }^{131}$ Sulfasalazine is of low risk during breastfeeding as confirmed by multiple prospective clinical trials. ${ }^{132}$ Though sulfapyridine moiety is absorbed in minimal amounts and is excreted in breast milk, the milk/serum ratio is acceptable. ${ }^{131,133}$

\section{Side Effects and Monitoring of 5-ASAs}

\section{Statement 28}

5-ASA is well tolerated by most patients.

- Grade of recommendation: A, Level of evidence: I, Voting: $100 \%$ strongly agree

A systematic review and meta-analysis showed that the likelihood of experiencing any adverse event with 5-ASAs was not statistically different when compared with placebo both for induction of remission (10 RCTs: RR, 1.02; 95\% CI, 0.81-1.29) and in prevention of relapse (5 RCTs: RR, 0.98; 95\% CI, 0.84-1.15). ${ }^{120}$

A Cochrane systematic review with 53 RCTs of parallel design, with minimum treatment duration of 4 weeks $(n=8,548)$ concluded that the difference in incidence of adverse events with 5-ASA agents and placebo did not reach statistical significance. However, sulfasalazine was not as well tolerated by the patients as 5-ASA (29\% vs. 15\% experiencing adverse events: 
RR, $0.48 ; 95 \%$ CI, 0.37-0.63) due to intolerance or hypersensitivity reactions that are often attributable to sulfapyridine moiety. ${ }^{26}$

\footnotetext{
Statement 29

Paradoxical worsening of colitis may occur on initiation of 5-ASA due to drug hypersensitivity and requires discontinuation of the drug.

- Grade of recommendation: A, Level of evidence: I, Voting: $66.7 \%$ strongly agree, $33.3 \%$ agree
}

A systematic review of 46 randomized trials on short-term adverse effects of 5-ASA agents in UC reported that approximately 3\% of patients on oral 5-ASA agents develop paradoxical worsening of their symptoms such as abdominal pain, diarrhea and blood in stools, and cramping. ${ }^{134}$ Symptoms usually disappear when 5-ASA agents are discontinued. These patients should be considered allergic to 5-ASAs, drug should be withdrawn, and no 5-ASA preparation should be used in these patients. ${ }^{134}$

The precise mechanism of exacerbation of colitis induced by 5-ASA is not clear. Scheurlen et al. ${ }^{135}$ mentioned that diarrhea caused by 5-ASA was attributed to a secretory mechanism secondary to inhibition of ileal and colonic $\mathrm{Na}^{+} \mathrm{K}^{+}$ ATPase. Another proposed mechanism is an alteration of arachidonic acid metabolism manifesting as secretory diarrhea and malabsorption.

\section{Statement 30}

5-ASA may cause renal toxicity and therefore monitoring of renal function should be carried out at least once in a year.

- Grade of recommendation: A, Level of evidence: I, Voting: $63.6 \%$ strongly agree, $31.8 \%$ agree, $4.5 \%$ disagree

Nephrotoxicity is a rare adverse effect of 5-ASA therapy. Muller et al. ${ }^{136}$ reported the incidence of nephrotoxicity in patients with IBD taking 5-ASA to be about 1/4,000 patients/year. Another systematic review reported less than $0.5 \%$ incidence of nephrotoxicity in patients with IBD consuming 5-ASA. ${ }^{137} 5$-ASArelated nephrotoxicity includes interstitial nephritis, glomerulonephritis, and minimal-change nephropathy with nephrotic syndrome.$^{138}$ Renal impairment is reported to occur as early as within 29 days and as late as 5 years; ${ }^{136,139} 50 \%$ of cases present within 1 year of treatment initiation. ${ }^{137}$ No relationship between type/dose of 5-ASA therapy and development of renal disease has been reported.

The time of diagnosis of 5-ASA nephrotoxicity and subsequent discontinuation of drug determines the course of renal impairment. ${ }^{140}$ A review showed that if 5-ASA-associated nephrotoxicity is diagnosed within 10 months of initiation of 5-ASA, then 5-ASA withdrawal alone reverses the nephrotoxicity in $85 \%$ of cases; but when the diagnosis was made after 18 months of initiation, partial recovery was observed in only one-third of patients. ${ }^{141}$

The Medicines Healthcare Regulatory Authority recommended checking serum creatinine levels at baseline and 3 monthly for the first year, 6 monthly for the next 4 years, and then annually. ${ }^{142}$

\section{Statement 31}

Dose modification is not required in chronic renal failure except that renal function should be monitored more closely.

- Grade of recommendation: C, Level of evidence: III, Voting: $52.0 \%$ strongly agree, $44.0 \%$ agree, $4.0 \%$ disagree

Patients with preexisting renal dysfunction may be more likely to suffer 5-ASA nephrotoxicity than those with normal renal function. ${ }^{143}$ There is lack of RCT on the safety of 5-ASA agents in IBD patients suffering from chronic kidney disease. ${ }^{137}$ IBD patients are more susceptible to renal damage during acute exacerbations, such as during an acute episode of diarrhea. ${ }^{137}$ Therefore, IBD patients with chronic kidney disease need close monitoring, ${ }^{144}$ especially in acute exacerbations of disease, in case of 5-ASA induced nephrotoxicity, and in patients with comorbid conditions known to affect renal functions, such as diabetes and hypertension. ${ }^{137,145-147}$

\section{Statement 32}

Although sulfasalazine has the potential to cause decreased fertility in men, 5-ASA formulations do not affect fertility in men or women.

- Grade of recommendation: B, Level of evidence: II-1, Voting: $47.6 \%$ strongly agree, $42.9 \%$ agree, $9.5 \%$ disagree

Various studies have shown the reversible adverse effect of sulfasalazine therapy on fertility in males with IBD. However, no such effects were observed on fertility of female patients. Infertility due to sulfasalazine in males is attributed to its sulfapyridine component rather than 5-ASA, the therapeutically active component. Sulfasalazine leads to changes in sperm morphology, decreased sperm motility and sperm count. ${ }^{127-129,131,133,148}$ Birnie et al. ${ }^{149}$ reported abnormal semen production and oligospermia in $86 \%$ and $72 \%$ patients respectively, treated with sulfasalazine. However, infertility in males is reversible and preventable by switching sulfasalazine to other 5-ASA formulations. ${ }^{6,150}$ Absence of sulfapyridine moiety in the newer 5-ASAs 
possibly mitigates the adverse effect of sulfasalazine on male fertility. $^{151}$

\section{Statement 33}

Folate supplementation is required with use of sulfasalazine, other 5-ASA formulations do not require it.

- Grade of recommendation: B, Level of evidence: II-3, Voting: $62.5 \%$ strongly agree, $29.2 \%$ agree, $4.2 \%$ disagree, $8.3 \%$ strongly disagree

Sulfasalazine therapy is known to decrease folate synthesis by inhibiting dihydrofolate reductase and reducing folate absorption. These effects are not observed with other 5-ASA formulations. ${ }^{129,152,153}$ Folic acid supplementation in sulfasalazine treated pregnant women, decreases the incidence of oral clefts, fetal neural tube defects and cardiovascular anomalies in newborns. ${ }^{129,152}$ Pregnant women with IBD being treated with sulfasalazine should receive higher doses of folic acid ( $2 \mathrm{mg} /$ day) than pregnant women without IBD. ${ }^{128,131,133,150}$

\section{Chemopreventive Role of 5-ASA}

\section{Statement 34}

Long-term 5-ASA therapy in extensive/distal colitis is possibly associated with reduced risk of colon cancer in UC.

- Grade of recommendation: B, Level of evidence: II-1, Voting: $26.9 \%$ strongly agree, $57.7 \%$ agree, $15.4 \%$ disagree

A systematic review (6 case-control studies) showed that 5-ASA use in IBD patients may have chemopreventive effect. Four of the 6 studies exhibited significant risk reduction with 5-ASA $(P<0.05)$, while risk reduction in the other 2 studies did not reach significance. ${ }^{154}$ Qiu et al.${ }^{155}$ in their systematic review and meta analysis (26 observational studies; 15,460 patients) also reported significant decrease in colorectal cancer (CRC) in UC patients (OR, 0.46; 95\% CI, 0.34-0.61) but not in CD patients (OR, 0.66; 95\% CI, 0.42-1.03). 5-ASA use correlated significantly with CRC (OR, $0.54 ; 95 \%$ CI, $0.39-0.74)$ but not with dysplasia (OR, 0.47; 95\% CI, 0.20-1.10). The meta-analysis further showed significant protective effect of 5-ASA only in clinical studies (OR, 0.51; 95\% CI, 0.39-0.65) and not in population-based studies (OR, 0.71; 95\% CI, 0.46-1.09).

Another systematic review and meta-analysis of 17 observational case-control, retrospective cohort, population- and hospital-based studies showed that the use of 5-ASA correlated with reduced risk of CRC in UC (OR, 0.63; 95\% CI, $0.48-$ 0.84). ${ }^{156}$ The chemopreventive efficacy of 5-ASA increased with higher average daily dose (sulfasalazine $\geq 2 \mathrm{~g}$ /day and
5-ASA $\geq 1.2 \mathrm{~g} /$ day; pooled OR, 0.51; 95\% CI, 0.35-0.75). Population-based studies in this systematic review and meta-analysis also did not show significant chemo-protective effect. ${ }^{156} \mathrm{In}$ another systematic review 5-ASA use was found to be protective for CRC (RR, 0.70; 95\% CI, 0.51-0.94) and the effect was dose-dependent; the effect with sulfasalazine was marginally nonsignificant (RR, 0.72; 95\% CI, 0.51-1.01). ${ }^{157}$

A population-based study from the University of Manitoba IBD Epidemiology Database did not endorse the chemo-protective effect of 5-ASA for CRC. HRs for CRC among 5-ASA users were 1.04 ( $\geq 1$ year of use: $95 \% \mathrm{CI}, 0.67-1.62 ; P=0.87$ ) and 2.01 ( $\geq 5$ years of use: $95 \% \mathrm{CI}, 1.04-3.9 ; P=0.038$ ). Males, but not females, using 5-ASA for $\geq 5$ years had an increased risk of CRC. ${ }^{158}$

\section{Adherence to 5-ASA Therapy}

\section{Statement 35}

Adherence to 5-ASA therapy improves outcome in patients with IBD. Hence, patient education is important.

- Grade of recommendation: B, Level of evidence: II-2, Voting: $56.5 \%$ strongly agree, $39.1 \%$ agree, $4.3 \%$ disagree

Adherence to medication plays a significant role in the management of IBD as patients need long-term therapy. Non-adherence lowers the effectiveness of treatment and also increases cost of therapy. Non-adherence to therapy is a major concern. A self-reported survey from India revealed that $81 \%$ of patients were non-adherent to treatment, defined as taking $80 \%$ or less of the dose advised. The reasons for non-adherence (not mutually exclusive) were forgetfulness (77\%), felt better (14.2\%), high frequency of doses (10.1\%), no effect of medications $(7.9 \%)$, and non-availability of medications (2.3\%). Non-adherent patients were three times more likely to develop a relapse as compared to those with adherence (OR, 3.38; 95\% CI, 1.29-8.88; $P=0.012) .{ }^{159}$

In contrast, another study from northern India (266 IBD patients) showed that more than $80 \%$ of patients were adherent to their medications, adherence being the least for topical therapy. Higher education, professional occupation, and upper socio-economic status were associated with lower adherence to medications. ${ }^{160}$ Two cohort studies found that non-adherent patients are likely to experience greater risk of disease relapse compared to those who are adherent (HR, 5.5; 95\% CI, $2.3-13 ; P<0.001$ and RR, 1.44; 95\% CI, $1.08-1.94 ; P=0.014$, respectively). ${ }^{161,162}$

Although there is paucity of data on the impact of health ed- 

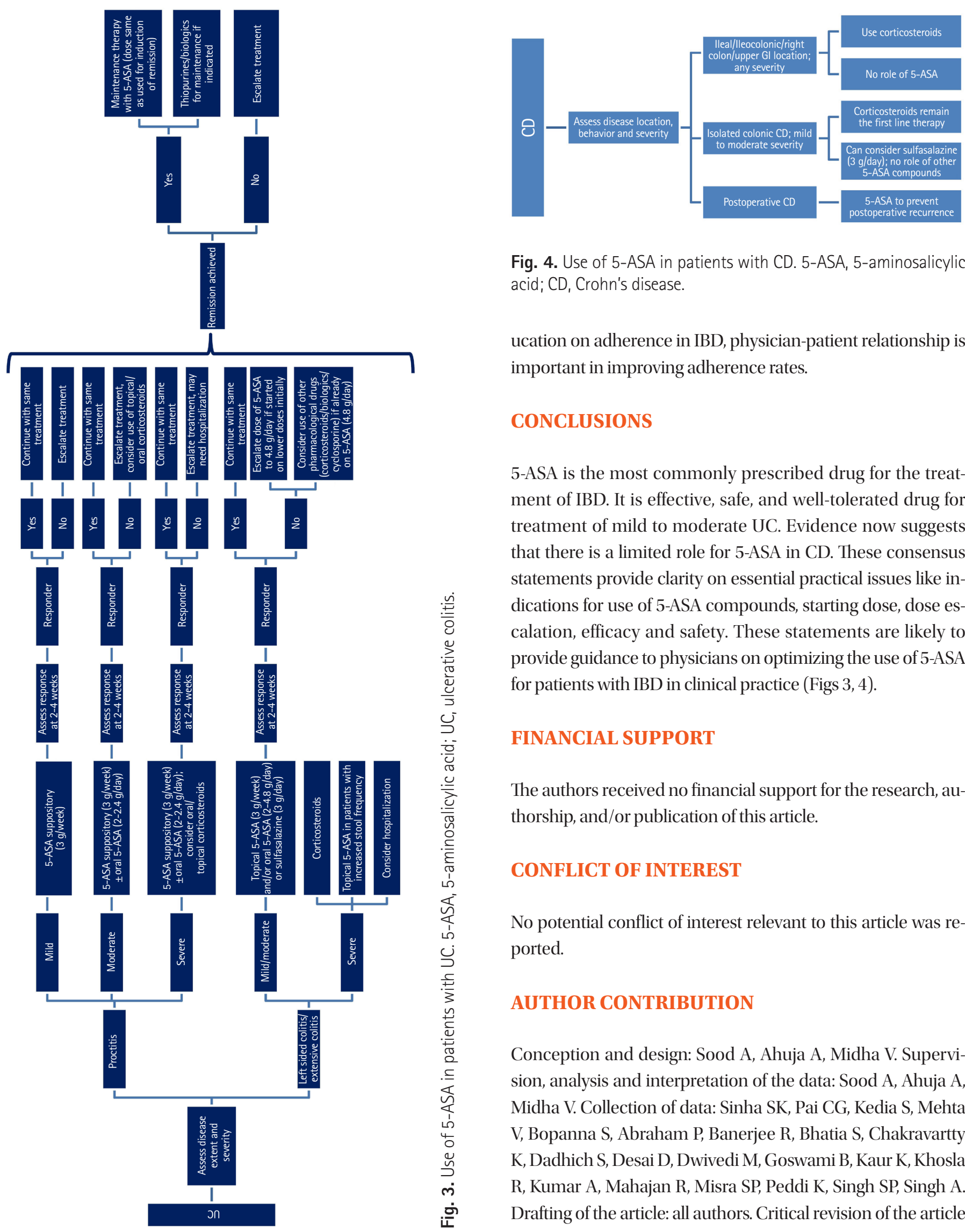

Fig. 4. Use of 5-ASA in patients with CD. 5-ASA, 5-aminosalicylic acid; CD, Crohn's disease.

ucation on adherence in IBD, physician-patient relationship is important in improving adherence rates.

\section{CONCLUSIONS}

5-ASA is the most commonly prescribed drug for the treatment of IBD. It is effective, safe, and well-tolerated drug for treatment of mild to moderate UC. Evidence now suggests that there is a limited role for 5-ASA in CD. These consensus statements provide clarity on essential practical issues like indications for use of 5-ASA compounds, starting dose, dose escalation, efficacy and safety. These statements are likely to provide guidance to physicians on optimizing the use of 5-ASA for patients with IBD in clinical practice (Figs 3,4).

\section{FINANCIAL SUPPORT}

The authors received no financial support for the research, authorship, and/or publication of this article.

\section{CONFLICT OF INTEREST}

No potential conflict of interest relevant to this article was reported.

\section{AUTHOR CONTRIBUTION}

Conception and design: Sood A, Ahuja A, Midha V. Supervision, analysis and interpretation of the data: Sood A, Ahuja A, Midha V. Collection of data: Sinha SK, Pai CG, Kedia S, Mehta V, Bopanna S, Abraham P, Banerjee R, Bhatia S, Chakravartty K, Dadhich S, Desai D, Dwivedi M, Goswami B, Kaur K, Khosla R, Kumar A, Mahajan R, Misra SP, Peddi K, Singh SP, Singh A. 을 Drafting of the article: all authors. Critical revision of the article 
for important intellectual content: all authors. Final approval of the article: all authors.

\section{ORCID}

$\begin{array}{ll}\text { Sood A } & \text { https://orcid.org/0000-0001-6961-6389 } \\ \text { Ahuja V } & \text { https://orcid.org/0000-0002-1577-0118 } \\ \text { Midha V } & \text { https://orcid.org/0000-0003-0192-3969 } \\ \text { Sinha SK } & \text { https://orcid.org/0000-0001-8088-9935 } \\ \text { Pai CG } & \text { https://orcid.org/0000-0003-4676-6282 } \\ \text { Kedia S } & \text { https://orcid.org/0000-0002-5758-0144 } \\ \text { Banerjee R } & \text { https://orcid.org/0000-0002-3753-4933 } \\ \text { Bhatia S } & \text { https://orcid.org/0000-0001-6132-0356 } \\ \text { Desai D } & \text { https://orcid.org/0000-0002-9741-5549 } \\ \text { Kaur K } & \text { https://orcid.org/0000-0002-0951-7415 } \\ \text { Mahajan R } & \text { https://orcid.org/0000-0001-6726-6151 } \\ \text { Singh A } & \text { https://orcid.org/0000-0001-7163-0454 }\end{array}$

\section{ACKNOWLEDGMENTS}

The authors acknowledge the participation and inputs of Charles N Bernstein (University of Manitoba IBD Clinical and Research Centre, Max Rady College of Medicine, Rady Faculty of Health Sciences, University of Manitoba, Winnipeg, Manitoba, Canada), Bo Shen (Columbia University Irving Medical Center, New York, USA) and Gursimran Kochar (Allegheny General Hospital, Pennsylvania, USA) in the formulation of this draft. The authors would also like to acknowledge Turacoz Healthcare Solutions (www.Turacoz.com), Gurugram, India, and Ferring (India), for their unrestricted educational support.

\section{REFERENCES}

1. Coward S, Kaplan GG. IBD in the new world, old world, and your world. In: Cohen RD, ed. Inflammatory bowel disease: diagnosis and therapeutics. 3rd ed. Cham: Springer, 2017:1327.

2. Singh P, Ananthakrishnan A, Ahuja V. Pivot to Asia: inflammatory bowel disease burden. Intest Res 2017;15:138-141.

3. Kedia S, Ahuja V. Epidemiology of inflammatory bowel disease in India: the great shift East. Inflamm Intest Dis 2017;2: 102-115.

4. Karagozian R, Burakoff R. The role of mesalamine in the treatment of ulcerative colitis. Ther Clin Risk Manag 2007;3:893903.
5. Rousseaux C, Lefebvre B, Dubuquoy L, et al. Intestinal antiinflammatory effect of 5-aminosalicylic acid is dependent on peroxisome proliferator-activated receptor-gamma. J Exp Med 2005;201:1205-1215.

6. Abdu-Allah HH, El-Shorbagi AN, Abdel-Moty SG, El-Awady R, Abdel-Alim AA. 5-Aminosalyclic acid (5-ASA): a unique anti-inflammatory salicylate. Med Chem (Los Angeles) 2016;6:306-315.

7. Hanauer SB. Review article: aminosalicylates in inflammatory bowel disease. Aliment Pharmacol Ther 2004;20 Suppl 4:60-65.

8. Ye B, van Langenberg DR. Mesalazine preparations for the treatment of ulcerative colitis: are all created equal? World J Gastrointest Pharmacol Ther 2015;6:137-144.

9. Williams C, Panaccione R, Ghosh S, Rioux K. Optimizing clinical use of mesalazine (5-aminosalicylic acid) in inflammatory bowel disease. Therap Adv Gastroenterol 2011;4:237248.

10. Ham M, Moss AC. Mesalamine in the treatment and maintenance of remission of ulcerative colitis. Expert Rev Clin Pharmacol 2012;5:113-123.

11. Sellin JH, Pasricha PJ. Pharmacotherapy of inflammatory bowel diseases. In: Brunton LL, Lazo JS, Parker KL, eds. Goodman \& Gilman's the pharmacological basis of therapeutics. 10th ed. New York: McGraw-Hill Companies, 2006: 1009-1011.

12. D'Incà R, Paccagnella M, Cardin R, et al. 5-ASA colonic mucosal concentrations resulting from different pharmaceutical formulations in ulcerative colitis. World J Gastroenterol 2013; 19:5665-5670.

13. Bodagala VR, Korlakunta NJ, Ambati SR. Design and evaluation of novel high-load mesalamine multi-particulate formulations for colon-targeted controlled drug delivery. J Compr Pharm 2016;3:209-219.

14. Böhm SK, Kruis W. Long-term efficacy and safety of oncedaily mesalazine granules for the treatment of active ulcerative colitis. Clin Exp Gastroenterol 2014;7:369-383.

15. NHS. Mesalazine, medicines information. Oxford University Hospitals NHS Foundation Trust Web site. https://www.ouh. nhs.uk/patient-guide/leaflets/files/100722paedmesalazine. pdf. Accessed October 18, 2019.

16. Sandborn WJ, Hanauer SB. Systematic review: the pharmacokinetic profiles of oral mesalazine formulations and mesalazine pro-drugs used in the management of ulcerative colitis. Aliment Pharmacol Ther 2003;17:29-42.

17. Guyatt G, Oxman AD, Akl EA, et al. GRADE guidelines: 1. in- 
troduction-GRADE evidence profiles and summary of findings tables. J Clin Epidemiol 2011;64:383-394.

18. Guyatt GH, Oxman AD, Vist G, et al. GRADE guidelines: 4. rating the quality of evidence: study limitations (risk of bias). J Clin Epidemiol 2011;64:407-415.

19. Canadian Task Force on the Periodic Health Examination. The periodic health examination. Can Med Assoc J 1979;121: 1193-1254.

20. Ramakrishna BS, Makharia GK, Abraham P, et al. Indian Society of Gastroenterology consensus on ulcerative colitis. Indian J Gastroenterol 2012;31:307-323.

21. Linstone H, Turoff $M$. The Delphi method: techniques and application. New Jersey Institute of Technology Web site. https://web.njit.edu/ turoff/pubs/delphibook/delphibook. pdf. Accessed October 18, 2019.

22. Baron JH, Connell AM, Lennard-Jones JE, Jones FA. Sulphasalazine and salicylazosulphadimidine in ulcerative colitis. Lancet 1962;1:1094-1096.

23. Dick AP, Grayson MJ, Carpenter RG, Petrie A. Controlled trial of sulphasalazine in the treatment of ulcerative colitis. Gut 1964;5:437-442.

24. Nguyen NH, Fumery M, Dulai PS, et al. Comparative efficacy and tolerability of pharmacological agents for management of mild to moderate ulcerative colitis: a systematic review and network meta-analyses. Lancet Gastroenterol Hepatol 2018;3:742-753.

25. Feagan BG, Macdonald JK. Oral 5-aminosalicylic acid for induction of remission in ulcerative colitis. Cochrane Database Syst Rev 2012;10:CD000543.

26. Wang Y, Parker CE, Bhanji T, Feagan BG, MacDonald JK. Oral 5-aminosalicylic acid for induction of remission in ulcerative colitis. Cochrane Database Syst Rev 2016;4:CD000543.

27. Probert C. Steroids and 5-aminosalicylic acids in moderate ulcerative colitis: addressing the dilemma. Therap Adv Gastroenterol 2013;6:33-38.

28. Campieri M, Adamo S, Valpiani D, et al. Oral beclometasone dipropionate in the treatment of extensive and left-sided active ulcerative colitis: a multicentre randomised study. Aliment Pharmacol Ther 2003;17:1471-1480.

29. Suzuki Y, Iida M, Ito H, Saida I, Hibi T. Efficacy and safety of two pH-dependent-release mesalamine doses in moderately active ulcerative colitis: a multicenter, randomized, doubleblind, parallel-group study. Intest Res 2016;14:50-59.

30. Mansfield JC, Giaffer MH, Cann PA, McKenna D, Thornton PC, Holdsworth CD. A double-blind comparison of balsalazide, $6.75 \mathrm{~g}$, and sulfasalazine, $3 \mathrm{~g}$, as sole therapy in the man- agement of ulcerative colitis. Aliment Pharmacol Ther 2002; 16:69-77.

31. Ford AC, Khan KJ, Achkar JP, Moayyedi P. Efficacy of oral vs. topical, or combined oral and topical 5-aminosalicylates, in ulcerative colitis: systematic review and meta-analysis. Am J Gastroenterol 2012;107:167-176.

32. McCormack PL, Robinson DM, Perry CM. Delayed-release multi matrix system (MMX) mesalazine: in ulcerative colitis. Drugs 2007;67:2635-2642.

33. Li W, Zhang ZM, Jiang XL. Once daily vs multiple daily mesalamine therapy for mild to moderate ulcerative colitis: a meta-analysis. Colorectal Dis 2016;18:0214-O223.

34. Keil R, Wasserbauer M, Zádorová Z, et al. Adherence, risk factors of non-adherence and patient's preferred treatment strategy of mesalazine in ulcerative colitis: multicentric observational study. Scand J Gastroenterol 2018;53:459-465.

35. Tong JL, Huang ML, Xu XT, Qiao YQ, Ran ZH. Once-daily versus multiple-daily mesalamine for patients with ulcerative colitis: a meta-analysis. J Dig Dis 2012;13:200-207.

36. Orchard TR, van der Geest SA, Travis SP. Randomised clinical trial: early assessment after 2 weeks of high-dose mesalazine for moderately active ulcerative colitis: new light on a familiar question. Aliment Pharmacol Ther 2011;33:1028-1035.

37. Hanauer SB, Sandborn WJ, Dallaire C, et al. Delayed-release oral mesalamine $4.8 \mathrm{~g} /$ day (800 mg tablets) compared to 2.4 g/day (400 mg tablets) for the treatment of mildly to moderately active ulcerative colitis: the ASCEND I trial. Can J Gastroenterol 2007;21:827-834.

38. Hanauer SB, Sandborn WJ, Kornbluth A, et al. Delayed-release oral mesalamine at $4.8 \mathrm{~g} /$ day ( $800 \mathrm{mg}$ tablet) for the treatment of moderately active ulcerative colitis: the ASCEND II trial. Am J Gastroenterol 2005;100:2478-2485.

39. Sandborn WJ, Regula J, Feagan BG, et al. Delayed-release oral mesalamine $4.8 \mathrm{~g} /$ day (800-mg tablet) is effective for patients with moderately active ulcerative colitis. Gastroenterology 2009;137:1934-1943.

40. Peluso R, Manguso F, Vitiello M, Iervolino S, Di Minno MN. Management of arthropathy in inflammatory bowel diseases. Ther Adv Chronic Dis 2015;6:65-77.

41. Smale S, Natt RS, Orchard TR, Russell AS, Bjarnason I. Inflammatory bowel disease and spondylarthropathy. Arthritis Rheum 2001;44:2728-2736.

42. Orchard TR, Wordsworth BP, Jewell DP. Peripheral arthropathies in inflammatory bowel disease: their articular distribution and natural history. Gut 1998;42:387-391.

43. Voulgari PV. Rheumatological manifestations in inflammato- 
ry bowel disease. Ann Gastroenterol 2011;24:173-180.

44. Lakatos PL, Lakatos L, Kiss LS, Peyrin-Biroulet L, Schoepfer A, Vavricka S. Treatment of extraintestinal manifestations in inflammatory bowel disease. Digestion 2012;86 Suppl 1:2835 .

45. Olivieri I, Cantini F, Castiglione F, et al. Italian Expert Panel on the management of patients with coexisting spondyloarthritis and inflammatory bowel disease. Autoimmun Rev 2014;13: 822-830.

46. Van der Heijde D, Ramiro S, Landewé R, et al. 2016 update of the ASAS-EULAR management recommendations for axial spondyloarthritis. Ann Rheum Dis 2017;76:978-991.

47. Mowat C, Cole A, Windsor A, et al. Guidelines for the management of inflammatory bowel disease in adults. Gut 2011; 60:571-607.

48. Macken L, Blaker PA. Management of acute severe ulcerative colitis (NICE CG 166). Clin Med (Lond) 2015;15:473-476.

49. Doherty G, Bennett G, Patil S, Cheifetz A, Moss AC. Interventions for prevention of post-operative recurrence of Crohn's disease. Cochrane Database Syst Rev 2009;(4):CD006873.

50. Bitton A, Buie D, Enns R, et al. Treatment of hospitalized adult patients with severe ulcerative colitis: Toronto consensus statements. Am J Gastroenterol 2012;107:179-194.

51. Feagan BG, Macdonald JK. Oral 5-aminosalicylic acid for maintenance of remission in ulcerative colitis. Cochrane Database Syst Rev 2012;10:CD000544.

52. Paoluzi OA, Iacopini F, Pica R, et al. Comparison of two different daily dosages (2.4 vs. $1.2 \mathrm{~g}$ ) of oral mesalazine in maintenance of remission in ulcerative colitis patients: 1-year follow-up study. Aliment Pharmacol Ther 2005;21:1111-1119.

53. Wright R, Truelove SR. Serial rectal biopsy in ulcerative colitis during the course of a controlled therapeutic trial of various diets. Am J Dig Dis 1966;11:847-857.

54. Meucci G, Fasoli R, Saibeni S, et al. Prognostic significance of endoscopic remission in patients with active ulcerative colitis treated with oral and topical mesalazine: a prospective, multicenter study. Inflamm Bowel Dis 2012;18:1006-1010.

55. Colombel JF, Rutgeerts P, Reinisch W, et al. Early mucosal healing with infliximab is associated with improved longterm clinical outcomes in ulcerative colitis. Gastroenterology 2011;141:1194-1201.

56. Ardizzone S, Cassinotti A, Duca P, et al. Mucosal healing predicts late outcomes after the first course of corticosteroids for newly diagnosed ulcerative colitis. Clin Gastroenterol Hepatol 2011;9:483-489.

57. Frøslie KF, Jahnsen J, Moum BA, Vatn MH; IBSEN Group.
Mucosal healing in inflammatory bowel disease: results from a Norwegian population-based cohort. Gastroenterology 2007;133:412-422.

58. Annese V, Daperno M, Rutter MD, et al. European evidence based consensus for endoscopy in inflammatory bowel disease. J Crohns Colitis 2013;7:982-1018.

59. Rubin DT, LoSavio A, Yadron N, Huo D, Hanauer SB. Aminosalicylate therapy in the prevention of dysplasia and colorectal cancer in ulcerative colitis. Clin Gastroenterol Hepatol 2006;4:1346-1350.

60. Rutter M, Saunders B, Wilkinson K, et al. Severity of inflammation is a risk factor for colorectal neoplasia in ulcerative colitis. Gastroenterology 2004;126:451-459.

61. Zahn A, Hinz U, Karner M, Ehehalt R, Stremmel W. Healthrelated quality of life correlates with clinical and endoscopic activity indexes but not with demographic features in patients with ulcerative colitis. Inflamm Bowel Dis 2006;12:1058-1067.

62. Feagan BG, Reinisch W, Rutgeerts P, et al. The effects of infliximab therapy on health-related quality of life in ulcerative colitis patients. Am J Gastroenterol 2007;102:794-802.

63. Khan N, Abbas AM, Koleva YN, Bazzano LA. Long-term mesalamine maintenance in ulcerative colitis: which is more important? Adherence or daily dose. Inflamm Bowel Dis 2013;19:1123-1129.

64. Fukuda T, Naganuma M, Sugimoto S, et al. The risk factor of clinical relapse in ulcerative colitis patients with low dose 5-aminosalicylic acid as maintenance therapy: a report from the IBD registry. PLoS One 2017;12:e0187737.

65. Ardizzone S, Petrillo M, Imbesi V, Cerutti R, Bollani S, Bianchi Porro G. Is maintenance therapy always necessary for patients with ulcerative colitis in remission? Aliment Pharmacol Ther 1999;13:373-379.

66. Takahashi F, Tominaga K, Kanamori A, et al. Timing for dosedown of 5-ASA depends on mucosal status with ulcerative colitis. Scand J Gastroenterol 2016;51:827-834.

67. Rubin DT, Bradette M, Gabalec L, et al. Ulcerative colitis remission status after induction with mesalazine predicts maintenance outcomes: the MOMENTUM trial. J Crohns Colitis 2016;10:925-933.

68. Velayos FS, Terdiman JP, Walsh JM. Effect of 5-aminosalicylate use on colorectal cancer and dysplasia risk: a systematic review and metaanalysis of observational studies. Am J Gastroenterol 2005;100:1345-1353.

69. Fockens P, Mulder CJ, Tytgat GN, et al. Comparison of the efficacy and safety of 1.5 compared with $3.0 \mathrm{~g}$ oral slow-release mesalazine (Pentasa) in the maintenance treatment of ulcer- 
ative colitis. Dutch Pentasa Study Group. Eur J Gastroenterol Hepatol 1995;7:1025-1030.

70. Mañosa M, Cabré E, Garcia-Planella E, et al. Decision tree for early introduction of rescue therapy in active ulcerative colitis treated with steroids. Inflamm Bowel Dis 2011;17:24972502.

71. Faubion WA Jr, Loftus EV Jr, Harmsen WS, Zinsmeister AR, Sandborn WJ. The natural history of corticosteroid therapy for inflammatory bowel disease: a population-based study. Gastroenterology 2001;121:255-260.

72. Ho GT, Chiam P, Drummond H, Loane J, Arnott ID, Satsangi J. The efficacy of corticosteroid therapy in inflammatory bowel disease: analysis of a 5-year UK inception cohort. Aliment Pharmacol Ther 2006;24:319-330.

73. Bello C, Belaiche J, Louis E, Reenaers C. Evolution and predictive factors of relapse in ulcerative colitis patients treated with mesalazine after a first course of corticosteroids. J Crohns Colitis 2011;5:196-202.

74. Khan N, Abbas A, Williamson A, Balart L. Prevalence of corticosteroids use and disease course after initial steroid exposure in ulcerative colitis. Dig Dis Sci 2013;58:2963-2969.

75. Garcia-Planella E, Mañosa M, Van Domselaar M, et al. Longterm outcome of ulcerative colitis in patients who achieve clinical remission with a first course of corticosteroids. Dig Liver Dis 2012;44:206-210.

76. Kornbluth A, Sachar DB; Practice Parameters Committee of the American College of Gastroenterology. Ulcerative colitis practice guidelines in adults: American College of Gastroenterology, Practice Parameters Committee. Am J Gastroenterol 2010;105:501-523.

77. Sninsky CA. New research in ulcerative colitis: optimizing 5-ASA administration for efficacy and adherence. Gastroenterol Hepatol (N Y) 2010;6(1 Suppl 1):4-16.

78. Marteau P, Crand J, Foucault M, Rambaud JC. Use of mesalazine slow release suppositories $1 \mathrm{~g}$ three times per week to maintain remission of ulcerative proctitis: a randomised double blind placebo controlled multicentre study. Gut 1998; 42:195-199.

79. Hanauer S, Good LI, Goodman MW, et al. Long-term use of mesalamine (Rowasa) suppositories in remission maintenance of ulcerative proctitis. Am J Gastroenterol 2000;95:17491754.

80. Lie MR, Kanis SL, Hansen BE, van der Woude CJ. Drug therapies for ulcerative proctitis: systematic review and metaanalysis. Inflamm Bowel Dis 2014;20:2157-2178.

81. Ford AC, Khan KJ, Sandborn WJ, Hanauer SB, Moayyedi P.
Efficacy of topical 5-aminosalicylates in preventing relapse of quiescent ulcerative colitis: a meta-analysis. Clin Gastroenterol Hepatol 2012;10:513-519.

82. Marshall JK, Thabane M, Steinhart AH, Newman JR, Anand A, Irvine EJ. Rectal 5-aminosalicylic acid for maintenance of remission in ulcerative colitis. Cochrane Database Syst Rev 2012;11:CD004118.

83. d'Albasio G, Pacini F, Camarri E, et al. Combined therapy with 5-aminosalicylic acid tablets and enemas for maintaining remission in ulcerative colitis: a randomized double-blind study. Am J Gastroenterol 1997;92:1143-1147.

84. Yokoyama H, Takagi S, Kuriyama S, et al. Effect of weekend 5-aminosalicylic acid (mesalazine) enema as maintenance therapy for ulcerative colitis: results from a randomized controlled study. Inflamm Bowel Dis 2007;13:1115-1120.

85. Moody GA, Eaden JA, Helyes Z, Mayberry JF. Oral or rectal administration of drugs in IBD? Aliment Pharmacol Ther 1997;11:999-1000.

86. Boyle M, Ting A, Cury DB, Nanda K, Cheifetz AS, Moss A. Adherence to rectal mesalamine in patients with ulcerative colitis. Inflamm Bowel Dis 2015;21:2873-2878.

87. Kamm MA, Lichtenstein GR, Sandborn WJ, et al. Randomised trial of once- or twice-daily MMX mesalazine for maintenance of remission in ulcerative colitis. Gut 2008;57: 893-902.

88. Bokemeyer B, Hommes D, Gill I, Broberg P, Dignass A. Mesalazine in left-sided ulcerative colitis: efficacy analyses from the PODIUM trial on maintenance of remission and mucosal healing. J Crohns Colitis 2012;6:476-482.

89. Marshall JK, Irvine EJ. Rectal aminosalicylate therapy for distal ulcerative colitis: a meta-analysis. Aliment Pharmacol Ther 1995;9:293-300.

90. Seibold F, Fournier N, Beglinger C, et al. Topical therapy is underused in patients with ulcerative colitis. J Crohns Colitis 2014;8:56-63.

91. Römkens TE, Kampschreur MT, Drenth JP, van Oijen MG, de Jong DJ. High mucosal healing rates in 5-ASA-treated ulcerative colitis patients: results of a meta-analysis of clinical trials. Inflamm Bowel Dis 2012;18:2190-2198.

92. Farup PG, Hovde O, Halvorsen FA, Raknerud N, Brodin U. Mesalazine suppositories versus hydrocortisone foam in patients with distal ulcerative colitis: a comparison of the efficacy and practicality of two topical treatment regimens. Scand J Gastroenterol 1995;30:164-170.

93. Campieri M, Gionchetti P, Belluzzi A, et al. 5-Aminosalicylic acid as enemas or suppositories in distal ulcerative colitis? J 
Clin Gastroenterol 1988;10:406-409.

94. Regueiro M, Loftus EV Jr, Steinhart AH, Cohen RD. Medical management of left-sided ulcerative colitis and ulcerative proctitis: critical evaluation of therapeutic trials. Inflamm Bowel Dis 2006;12:979-994.

95. Lamet M. A multicenter, randomized study to evaluate the efficacy and safety of mesalamine suppositories $1 \mathrm{~g}$ at bedtime and $500 \mathrm{mg}$ twice daily in patients with active mild-tomoderate ulcerative proctitis. Dig Dis Sci 2011;56:513-522.

96. Andus T, Kocjan A, Müser M, et al. Clinical trial: a novel highdose $1 \mathrm{~g}$ mesalamine suppository (Salofalk) once daily is as efficacious as a 500-mg suppository thrice daily in active ulcerative proctitis. Inflamm Bowel Dis 2010;16:1947-1956.

97. Marshall JK, Thabane M, Steinhart AH, Newman JR, Anand A, Irvine EJ. Rectal 5-aminosalicylic acid for induction of remission in ulcerative colitis. Cochrane Database Syst Rev 2010;(1):CD004115.

98. Gionchetti P, Rizzello F, Venturi A, et al. Comparison of oral with rectal mesalazine in the treatment of ulcerative proctitis. Dis Colon Rectum 1998;41:93-97.

99. Caselli MG, Pinedo MG, Zúñiga DA, Alvarez LM. Active and refractory ulcerative proctitis: an update. Rev Med Chil 2010; 138:109-116.

100. Safdi M, DeMicco M, Sninsky C, et al. A double-blind comparison of oral versus rectal mesalamine versus combination therapy in the treatment of distal ulcerative colitis. Am J Gastroenterol 1997;92:1867-1871.

101. Probert CS, Dignass AU, Lindgren S, Oudkerk Pool M, Marteau P. Combined oral and rectal mesalazine for the treatment of mild-to-moderately active ulcerative colitis: rapid symptom resolution and improvements in quality of life. J Crohns Colitis 2014;8:200-207.

102. Marshall JK, Irvine EJ. Rectal corticosteroids versus alternative treatments in ulcerative colitis: a meta-analysis. Gut 1997;40:775-781.

103. Mulder CJ, Fockens P, Meijer JW, van der Heide H, Wiltink $\mathrm{EH}$, Tytgat GN. Beclomethasone dipropionate (3 mg) versus 5-aminosalicylic acid ( $2 \mathrm{~g}$ ) versus the combination of both (3 $\mathrm{mg} / 2 \mathrm{~g}$ ) as retention enemas in active ulcerative proctitis. Eur J Gastroenterol Hepatol 1996;8:549-553.

104. Nagahori M, Kochi S, Hanai H, et al. Real life results in using 5-ASA for maintaining mild to moderate UC patients in Japan, a multi-center study, OPTIMUM Study. BMC Gastroenterol 2017;17:47.

105. Lee HJ, Jung ES, Lee JH, et al. Long-term clinical outcomes and factors predictive of relapse after 5 -aminosalicylate or sulfasalazine therapy in patients with mild-to-moderate ulcerative colitis. Hepatogastroenterology 2012;59:1415-1420.

106. Ransford RA, Langman MJ. Sulphasalazine and mesalazine: serious adverse reactions re-evaluated on the basis of suspected adverse reaction reports to the Committee on Safety of Medicines. Gut 2002;51:536-539.

107. Narang V, Kaur R, Garg B, et al. Association of endoscopic and histological remission with clinical course in patients of ulcerative colitis. Intest Res 2018;16:55-61.

108. Van Hees PA, van Lier HJ, van Elteren PH, et al. Effect of sulphasalazine in patients with active Crohn's disease: a controlled double-blind study. Gut 1981;22:404-409.

109. Singleton JW. Results of treatment with sulfasalazine in the American multicenter study on the treatment of Crohn disease (National Cooperative Crohn's Disease Study). Z Gastroenterol Verh 1981;19:38-40.

110. Malchow H, Ewe K, Brandes JW, et al. European Cooperative Crohn's Disease Study (ECCDS): results of drug treatment. Gastroenterology 1984;86:249-266.

111. Lim WC, Wang Y, MacDonald JK, Hanauer S. Aminosalicylates for induction of remission or response in Crohn's disease. Cochrane Database Syst Rev 2016;7:CD008870.

112. Lindsay JO, Irving PM, Mantzaris GJ, Panés J; ECCO Education Committee and ECCO Governing Board. ECCO IBD Curriculum. J Crohns Colitis 2017;11:1039-1043.

113. Sobrado CW, Leal RF, Sobrado LF. Therapies for Crohn's disease: a clinical update. Arq Gastroenterol 2016;53:206-211.

114. Gordon M. 5-Aminosalicylates to maintain remission in Crohn's disease: interpreting conflicting systematic review evidence. World J Gastrointest Pharmacol Ther 2017;8:99 102.

115. Bradley GM, Oliva-Hemker M. Pediatric ulcerative colitis: current treatment approaches including role of infliximab. Biologics 2012;6:125-134.

116. Sokollik C, Fournier N, Rizzuti D, et al. The use of 5-aminosalicylic acid in children and adolescents with inflammatory bowel disease. J Clin Gastroenterol 2018;52:e87-e91.

117. Levine A, Yerushalmi B, Kori M, et al. Mesalamine enemas for induction of remission in oral mesalamine-refractory pediatric ulcerative colitis: a prospective cohort study. J Crohns Colitis 2017;11:970-974.

118. Winter HS, Krzeski P, Heyman MB, et al. High- and low-dose oral delayed-release mesalamine in children with mild-tomoderately active ulcerative colitis. J Pediatr Gastroenterol Nutr 2014;59:767-772.

119. Turner D, Yerushalmi B, Kori M, et al. Once- versus twice-dai- 
ly mesalazine to induce remission in paediatric ulcerative colitis: a randomised controlled trial. J Crohns Colitis 2017; 11:527-533.

120. Ford AC, Achkar JP, Khan KJ, et al. Efficacy of 5-aminosalicylates in ulcerative colitis: systematic review and meta-analysis. Am J Gastroenterol 2011;106:601-616.

121. Quiros JA, Heyman MB, Pohl JF, et al. Safety, efficacy, and pharmacokinetics of balsalazide in pediatric patients with mild-to-moderate active ulcerative colitis: results of a randomized, double-blind study. J Pediatr Gastroenterol Nutr 2009;49:571-579.

122. Ferry GD, Kirschner BS, Grand RJ, et al. Olsalazine versus sulfasalazine in mild to moderate childhood ulcerative colitis: results of the Pediatric Gastroenterology Collaborative Research Group Clinical Trial. J Pediatr Gastroenterol Nutr 1993;17:32-38.

123. Heyman MB, Kierkus J, Spénard J, Shbaklo H, Giguere M. Efficacy and safety of mesalamine suppositories for treatment of ulcerative proctitis in children and adolescents. Inflamm Bowel Dis 2010;16:1931-1939.

124. Nikfar S, Rahimi R, Rezaie A, Abdollahi M. A meta-analysis of the efficacy of sulfasalazine in comparison with 5-aminosalicylates in the induction of improvement and maintenance of remission in patients with ulcerative colitis. Dig Dis Sci 2009;54:1157-1170.

125. Cuffari C, Pierce D, Korczowski B, et al. Randomized clinical trial: pharmacokinetics and safety of multimatrix mesalamine for treatment of pediatric ulcerative colitis. Drug Des Devel Ther 2016;10:593-607.

126. Rahimi R, Nikfar S, Rezaie A, Abdollahi M. Pregnancy outcome in women with inflammatory bowel disease following exposure to 5-aminosalicylic acid drugs: a meta-analysis. Reprod Toxicol 2008;25:271-275.

127. Cury DB, Moss AC. Treatment of Crohn's disease in pregnant women: drug and multidisciplinary approaches. World J Gastroenterol 2014;20:8790-8795.

128. Hendy P, Chadwick G, Hart A. IBD: reproductive health, pregnancy and lactation. Frontline Gastroenterol 2015;6:38-43.

129. Habal FM, Kapila V. Inflammatory bowel disease and pregnancy: evidence, uncertainty and patient decision-making. Can J Gastroenterol 2009;23:49-53.

130. Gallinger ZR, Nguyen GC. Presence of phthalates in gastrointestinal medications: is there a hidden danger? World J Gastroenterol 2013;19:7042-7047.

131. van der Woude CJ, Ardizzone S, Bengtson MB, et al. The second European evidenced-based consensus on reproduction and pregnancy in inflammatory bowel disease. J Crohns Colitis 2015;9:107-124.

132. Silverman DA, Ford J, Shaw I, Probert CS. Is mesalazine really safe for use in breastfeeding mothers? Gut 2005;54:170-171.

133. Nielsen $\mathrm{OH}$, Maxwell C, Hendel J. IBD medications during pregnancy and lactation. Nat Rev Gastroenterol Hepatol 2014;11:116-127.

134. Loftus EV Jr, Kane SV, Bjorkman D. Systematic review: shortterm adverse effects of 5-aminosalicylic acid agents in the treatment of ulcerative colitis. Aliment Pharmacol Ther 2004 19:179-189.

135. Scheurlen C, Allgayer H, Kruis W, Erdmann E, Sauerbruch T. Effect of olsalazine and mesalazine on human ileal and colonic ( $\mathrm{Na}++\mathrm{K}+$ )-ATPase: a possible diarrhogenic factor? Clin Investig 1993;71:286-289.

136. Muller AF, Stevens PE, McIntyre AS, Ellison H, Logan RF. Experience of 5-aminosalicylate nephrotoxicity in the United Kingdom. Aliment Pharmacol Ther 2005;21:1217-1224.

140. Gisbert JP, González-Lama Y, Maté J. 5-Aminosalicylates and renal function in inflammatory bowel disease: a systematic review. Inflamm Bowel Dis 2007;13:629-638.

138. Oikonomou KA, Kapsoritakis AN, Stefanidis I, Potamianos SP. Drug-induced nephrotoxicity in inflammatory bowel disease. Nephron Clin Pract 2011;119:c89-c96.

139. Popoola J, Muller AF, Pollock L, O’Donnell P, Carmichael P, Stevens P. Late onset interstitial nephritis associated with mesalazine treatment. BMJ 1998;317:795-797.

140. Siddique N, Farmer C, Muller AF. Do gastroenterologists monitor their patients taking 5-amino-salicylates following initiation of treatment. Frontline Gastroenterol 2015;6:27-31.

141. World MJ, Stevens PE, Ashton MA, Rainford DJ. Mesalazineassociated interstitial nephritis. Nephrol Dial Transplant 1996;11:614-621.

142. The Medicines Healthcare Regulatory Authority (MHRA). Pentasa slow release tablets $\lg$ (mesalazine). https://www. medicines.org.uk/emc/product/4778/smpc. Updated October 2019. Accessed April 28, 2020.

143. Patel H, Barr A, Jeejeebhoy KN. Renal effects of long-term treatment with 5-aminosalicylic acid. Can J Gastroenterol 2009;23:170-176.

144. Tekin F, Ozutemiz O, Ilter T. 5-aminosalicylates in inflammatory bowel disease and chronic renal failure. Aliment Pharmacol Ther 2005;22:579.

145. Zallot C, Billioud V, Frimat L, Faure P, Peyrin-Biroulet L; CREGG (Club de Reflexion des cabinets et Groupes d'Hépato-Gastroentérologie). 5-Aminosalicylates and renal function moni- 
toring in inflammatory bowel disease: a nationwide survey. J Crohns Colitis 2013;7:551-555.

146. Coresh J, Byrd-Holt D, Astor BC, et al. Chronic kidney disease awareness, prevalence, and trends among U.S. adults, 1999 to 2000. J Am Soc Nephrol 2005;16:180-188.

147. Frimat L, Siewe G, Loos-Ayav C, Briançon S, Kessler M, Aubrège A. Chronic kidney disease: do generalists and nephrologists differ in their care? Nephrol Ther 2006;2:127-135.

148. Chatzinoff M, Guarino JM, Corson SL, Batzer FR, Friedman LS. Sulfasalazine-induced abnormal sperm penetration assay reversed on changing to 5-aminosalicylic acid enemas. Dig Dis Sci 1988;33:108-110.

149. Birnie GG, McLeod TI, Watkinson G. Incidence of sulphasalazine-induced male infertility. Gut 1981;22:452-455.

150. Mahadevan U. Fertility and pregnancy in the patient with inflammatory bowel disease. Gut 2006;55:1198-1206.

151. Sands K, Jansen R, Zaslau S, Greenwald D. Review article: the safety of therapeutic drugs in male inflammatory bowel disease patients wishing to conceive. Aliment Pharmacol Ther 2015;41:821-834.

152. Vermeire S, Carbonnel F, Coulie PG, et al. Management of inflammatory bowel disease in pregnancy. J Crohns Colitis 2012;6:811-823.

153. Halsted CH, Gandhi G, Tamura T. Sulfasalazine inhibits the absorption of folates in ulcerative colitis. N Engl J Med 1981; 305:1513-1517.

154. Beu J. Chemoprevention of colorectal cancer with 5-aminosalicylic acids in adult patients with inflammatory bowel disease. Semantic Scholar Web site. https://pdfs.semanticscholar.org/8176/442c71633e61fb83e5bcd4333c369aclbdb6.pdf. Updated August 14, 2010. Accessed October 18, 2019.
155. Qiu X, Ma J, Wang K, Zhang H. Chemopreventive effects of 5-aminosalicylic acid on inflammatory bowel disease-associated colorectal cancer and dysplasia: a systematic review with meta-analysis. Oncotarget 2017;8:1031-1045.

156. Zhao LN, Li JY, Yu T, Chen GC, Yuan YH, Chen QK. 5-Aminosalicylates reduce the risk of colorectal neoplasia in patients with ulcerative colitis: an updated meta-analysis. PLoS One 2014;9:e94208.

157. Bonovas S, Fiorino G, Lytras T, Nikolopoulos G, Peyrin-Biroulet L, Danese S. Systematic review with meta-analysis: use of 5-aminosalicylates and risk of colorectal neoplasia in patients with inflammatory bowel disease. Aliment Pharmacol Ther 2017;45:1179-1192.

158. Bernstein CN, Nugent Z, Blanchard JF. 5-aminosalicylate is not chemoprophylactic for colorectal cancer in IBD: a population based study. Am J Gastroenterol 2011;106:731-736.

159. Bhatt J, Patil S, Joshi A, Abraham P, Desai D. Self-reported treatment adherence in inflammatory bowel disease in Indian patients. Indian J Gastroenterol 2009;28:143-146.

160. Tomar SK, Kedia S, Singh N, et al. Higher education, professional occupation, and upper socioeconomic status are associated with lower adherence to medications in patients with inflammatory bowel disease. JGH Open 2019;3:302-309.

161. Kane S, Huo D, Aikens J, Hanauer S. Medication nonadherence and the outcomes of patients with quiescent ulcerative colitis. Am J Med 2003;114:39-43.

162. Robinson A, Hankins M, Wiseman G, Jones M. Maintaining stable symptom control in inflammatory bowel disease: a retrospective analysis of adherence, medication switches and the risk of relapse. Aliment Pharmacol Ther 2013;38:531538. 